\title{
Targeting ACLY sensitizes castration-resistant prostate cancer cells to $A R$ antagonism by impinging on an ACLY-AMPK-AR feedback mechanism
}

\author{
Supriya Shah ${ }^{1}$, Whitney J. Carriveau ${ }^{1}$, Jinyang Li ${ }^{1}$, Sydney L. Campbell ${ }^{1}$, Piotr K. \\ Kopinski ${ }^{5,6}$, Hee-Woong Lim², Natalie Daurio ${ }^{3}$, Sophie Trefely ${ }^{1}$, Kyoung-Jae Won ${ }^{2}$, \\ Douglas C. Wallace ${ }^{5}$, Constantinos Koumenis ${ }^{3}$, Anthony Mancuso ${ }^{1,4}$, Kathryn E. \\ Wellen $^{1}$ \\ ${ }^{1}$ Department of Cancer Biology, University of Pennsylvania Perelman School of Medicine, Philadelphia, PA 19104, USA \\ ${ }^{2}$ Department of Genetics, University of Pennsylvania Perelman School of Medicine, Philadelphia, PA 19104, USA \\ ${ }^{3}$ Department of Radiation Oncology, University of Pennsylvania Perelman School of Medicine, Philadelphia, PA 19104, USA \\ ${ }^{4}$ Department of Radiology, University of Pennsylvania Perelman School of Medicine, Philadelphia, PA 19104, USA \\ ${ }^{5}$ Center for Mitochondrial and Epigenomic Medicine, Children's Hospital of Philadelphia, Philadelphia, PA 19104, USA \\ ${ }^{6}$ Howard Hughes Medical Institute, Philadelphia, PA 19104, USA \\ Correspondence to: Kathryn E. Wellen, email: wellenk@exchange.upenn.edu
}

Keywords: acetyl-COA, prostate cancer, fatty acid metabolism, AMPK, ER stress

Received: December 22, $2015 \quad$ Accepted: May 08, $2016 \quad$ Published: May 27, 2016

\section{ABSTRACT}

The androgen receptor (AR) plays a central role in prostate tumor growth. Inappropriate reactivation of the AR after androgen deprivation therapy promotes development of incurable castration-resistant prostate cancer (CRPC). In this study, we provide evidence that metabolic features of prostate cancer cells can be exploited to sensitize CRPC cells to AR antagonism. We identify a feedback loop between ATPcitrate lyase (ACLY)-dependent fatty acid synthesis, AMPK, and the AR in prostate cancer cells that could contribute to therapeutic resistance by maintaining AR levels. When combined with an AR antagonist, ACLY inhibition in CRPC cells promotes energetic stress and AMPK activation, resulting in further suppression of AR levels and target gene expression, inhibition of proliferation, and apoptosis. Supplying exogenous fatty acids can restore energetic homeostasis; however, this rescue does not occur through increased $\beta$-oxidation to support mitochondrial ATP production. Instead, concurrent inhibition of ACLY and AR may drive excess ATP consumption as cells attempt to cope with endoplasmic reticulum (ER) stress, which is prevented by fatty acid supplementation. Thus, fatty acid metabolism plays a key role in coordinating ER and energetic homeostasis in CRPC cells, thereby sustaining AR action and promoting proliferation. Consistent with a role for fatty acid metabolism in sustaining AR levels in prostate cancer in vivo, $A R$ mRNA levels in human prostate tumors correlate positively with expression of ACLY and other fatty acid synthesis genes. The ACLY-AMPK-AR network can be exploited to sensitize CRPC cells to AR antagonism, suggesting novel therapeutic opportunities for prostate cancer.

\section{INTRODUCTION}

Prostate cancer is responsible for nearly 30,000 deaths each year in the United States alone [1]. While localized prostate cancer has a favorable prognosis, some patients present with or develop metastatic disease. The androgen receptor (AR) plays a central role in prostate tumorigenesis at both early and late stages of the disease. Patients with metastatic prostate cancer typically respond well to androgen deprivation therapy. However, tumors eventually develop resistance mechanisms that allow them to grow at castrate levels of androgen, resulting in a terminal disease known as castration-resistant prostate cancer (CRPC). In CRPC, AR activity frequently remains 
crucial for disease progression, with tumors acquiring resistance mechanisms that enable AR transcriptional activity even with very low circulating levels of its canonical ligand [2-7]. Second-generation AR antagonists such as enzalutamide (ENZ), which inhibit ligand binding to the AR, extend the lives of some CRPC patients, but are not curative $[4,8,9]$. Therefore, identification of more effective therapeutic approaches is urgently needed for CRPC patients.

In addition to aberrant AR signaling, prostate cancer cells exhibit metabolic rewiring, including upregulation of fatty acid synthesis $[10,11]$. Acetyl-CoA, the essential building block for fatty acid metabolism, plays crucial roles at the interface of metabolism, signaling, and gene regulation $[12,13]$. It is produced within mitochondria from pyruvate, as well as from catabolism of fatty acids and amino acids, in order to sustain the TCA cycle and mitochondrial ATP production. Citrate, the condensation product of acetyl-CoA and oxaloacetate, can be exported from mitochondria and cleaved by ATP-citrate lyase (ACLY), generating acetyl-CoA within the cytoplasm and nucleus. Outside of mitochondria, acetyl-CoA is used for de novo synthesis of fatty acids and cholesterol, as well as for the acetylation of histones and numerous other proteins [12-15].

The PI3K-AKT-mTORC1 pathway is commonly activated in prostate cancer, most frequently via PTEN loss; in metastatic disease, $49 \%$ of tumors exhibit alterations in this pathway [16]. Constitutive PI3KAKT pathway activation in cancer cells is associated with elevated ACLY-dependent acetyl-CoA production and histone acetylation [17]. Moreover, the PI3K-AKTmTORC1 pathway also drives de novo fatty acid synthesis [18-22].

There is substantial prior evidence that fatty acid metabolism is upregulated in prostate cancer and is regulated by the $\operatorname{AR}[10,11,23-25]$. For example, in a prostate cancer xenograft model, fatty acid synthesis genes are highly expressed in the primary tumor, suppressed following castration, and then upregulated as resistant tumors emerge, suggesting potential involvement of fatty acid metabolism in CRPC development [23]. Inhibiting lipogenic enzymes such as fatty acid synthase (FASN), acetyl-CoA carboxylase (ACC), or ACLY produces anti-cancer effects both in prostate cancer cell lines and mouse models [10, 26-30]. Activation of AMP-activated protein kinase (AMPK), which inhibits fatty acid synthesis by phosphorylating ACC [31], also inhibits prostate tumorigenesis [10, 3235]. Acetyl-CoA metabolism may also promote growth and proliferation through gene regulation. In yeast, high acetyl-CoA levels induce histone acetylation at the promoters of genes involved in growth and proliferation $[36,37]$. Similarly, acetyl-CoA promotes global histone acetylation and expression of pro-proliferative gene expression in cancer cells $[15,17,38]$, although the underlying mechanisms of gene regulation by acetyl-CoA are not fully clear. Histone acetylation has been shown to be important for AR recruitment to chromatin and transcriptional activity [39]. Thus, elevated production of nuclear-cytoplasmic acetyl-CoA may support prostate tumor growth through both lipid metabolism and gene regulation.

In this study, we identify a signaling network between ACLY-dependent fatty acid metabolism, AMPK, and the AR. We show that ACLY inhibition potentiates the action of ENZ in suppressing AR function, and combining the two drugs strongly inhibits proliferation and induces apoptosis in CRPC cells. Prior studies have demonstrated that the PI3K-AKT and AR pathways inhibit one another, and that AR inhibition drives hyper-activation of AKT [40, 41]. Constitutive AKT-mTORC1 pathway activation has also been shown to exacerbate dependence on de novo fatty acid synthesis for endoplasmic reticulum (ER) homeostasis [42-44]. In this study, we show that simultaneous targeting of ACLY and AR exploits these interconnected signaling and metabolic pathways to induce ER stress and AMPK activation, which then drives further AR suppression and cell death. Energetic stress due to concurrent inhibition of ACLY and AR appears to result at least in part from excess ATP consumption as cells attempt to resolve ER stress. Thus, these data identify a novel mechanism linking cellular metabolism to transcriptional control in prostate cancer cells and point towards new opportunities to exploit the ACLY-AMPKAR network for therapeutic benefit in patients with CRPC, a disease for which to date there remains no cure.

\section{RESULTS}

\section{ACLY inhibition sensitizes CRPC cells to AR antagonism}

CRPC cells depend on the AR, which remains transcriptionally active in CRPC even in the absence of exogenous ligand [5-7]. As a result, C4-2 CRPC cells continued to proliferate in androgen-depleted conditions and were only minimally inhibited by enzalutamide (ENZ) (Figure 1A). ACLY expression is elevated in human prostate cancer and correlates with $A R$ expression (Supplementary Figure S1A, S1B). An ACLY inhibitor (ACLYi; BMS-303141) impaired proliferation or induced death in androgen-depleted CRPC cells in a dosedependent manner (Supplementary Figure S1C). At a dose of ACLYi that moderately impaired proliferation, cells were strongly sensitized to ENZ (Figure 1A). Combining ACLYi with either of two AR antagonists (ENZ or bicalutamide) potently suppressed growth in both CRPC and hormone naïve AR+ prostate cancer cell lines (Figure 1B-1E). In contrast, cells that do not rely on the 
A.

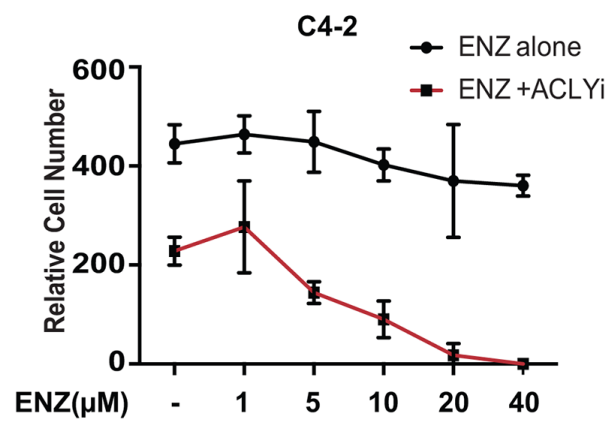

B.

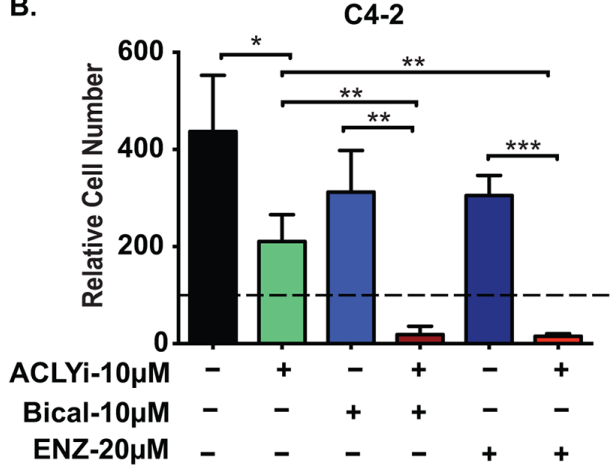

D.

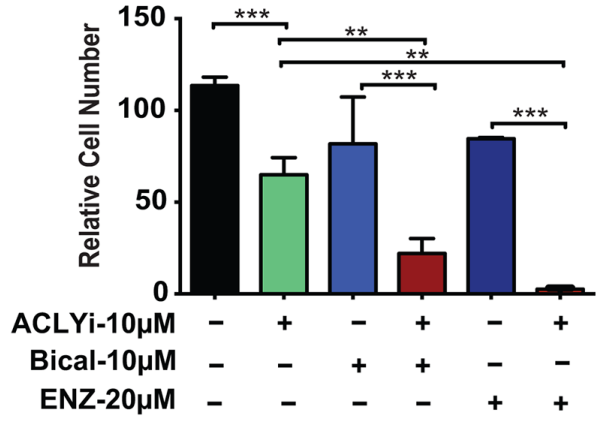

F.

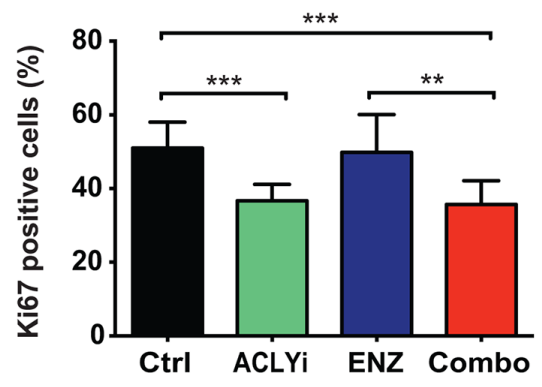

c.

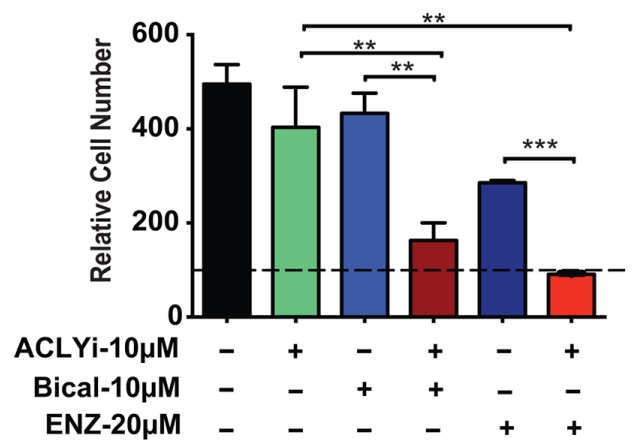

E.

LAPC-4

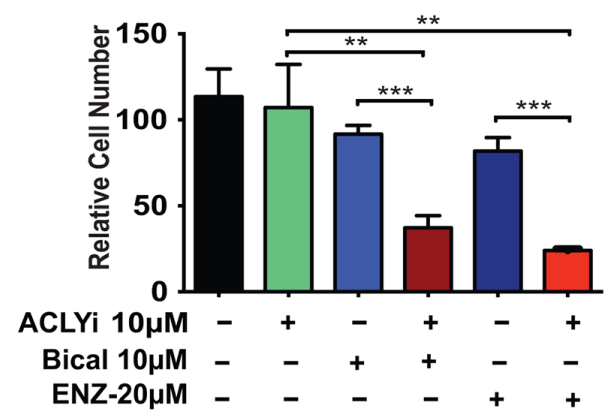

G.

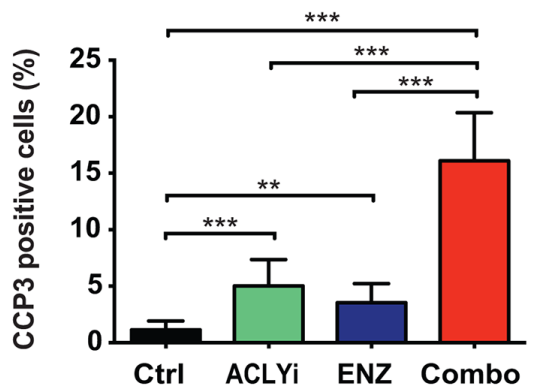

Figure 1: ACLY inhibition sensitizes castration-resistant prostate cancer cells to AR antagonism under androgen depletion. A. C4-2 cells were cultured in androgen-depleted conditions for 24 hours and then treated with doses of enzalutamide (ENZ) ranging from $0-40 \mu \mathrm{M}$, in the presence or absence of $10 \mu \mathrm{M}$ ACLY inhibitor (ACLYi; BMS-303141), for 72 hours. Cell number was quantitated relative to cell number at the start of inhibitor treatment and initial cell number set at 100. B-E. Indicated cell lines were cultured for 72 hours in androgen-depleted conditions, +/- ACLYi, ENZ, or Bicalutamide (Bical). Cell number was quantitated relative to starting cell number, set at 100 . F, G. Cells were treated for 24 hours with indicated inhibitors in androgen-depleted conditions. Immunofluorescent imaging was used to detect the proliferation indicator Ki67 (F) or apoptotic indicator cleaved caspase 3 (CCP3) (G). Data was quantified and graphed from 5 fields. For all values, mean $+/-$ SEM of triplicates is graphed; * ${ }^{*}<0.05 ; * *, p<0.01, * * *, p<0.001$. 
AR for proliferation such as PC-3 prostate cancer cells and 3T3-L1 preadipocytes were minimally impacted by the combination of ACLYi and ENZ (denoted hereafter as Combo) (Supplementary Figure S1D, S1E). The anti-proliferative effect in C4-2 cells, assessed by Ki67 positivity, was predominantly mediated by ACLYi, while the pro-apoptotic effect, assessed by cleaved-caspase 3 , was strongly potentiated by the Combo (Figure 1F, 1G). Similar results were obtained in C4-2 cells when ENZ was combined with either shRNA-mediated silencing of ACLY or a structurally distinct ACLY inhibitor, SB204990 [45] (Supplementary Figure S1F, S1G). When cells were cultured in standard FBS (not hormone-depleted), significant growth suppression was also observed with each inhibitor on its own, and this suppression was enhanced by combining the two (Supplementary Figure $\mathrm{S} 1 \mathrm{H})$. Thus, co-targeting ACLY and the AR effectively suppresses growth both in the presence and absence of exogenous androgen.

\section{Combining ACLY and AR inhibitors suppresses AR target gene expression}

Ligand-dependent and ligand-independent binding of the AR to chromatin, as well as androgen-dependent and androgen-independent CRPC gene signatures, have been previously defined in C4-2 cells [7]. "Androgenindependent" genes are those whose expression is enriched in C4-2 cells compared to the parental hormone-dependent cell line LNCaP. The AR also binds many of these genes in a ligand-independent manner [7]. As noted above, these cells continue to proliferate in the absence of androgen; however, both the AR and "androgen-independent" genes remain crucial for their growth [7]. We used these cells as a model of CRPC to interrogate the effects of ACLY/ AR inhibition on gene expression in CRPC cells. C4-2 cells were treated with DHT in the presence or absence of ENZ and/or ACLYi. As expected, AR target genes, including KLK3, FKBP5, and TMPRSS2, were induced by DHT, and their induction was inhibited by ENZ, which inhibits ligand binding to the AR [9] (Figure 2A). ACLYi also significantly suppressed expression of $K L K 3$ [encoding prostate specific antigen, (PSA)] on its own, and further suppressed its expression in the presence of ENZ (Figure 2A). Under androgen-depleted conditions, the Combo suppressed expression of the $A R$ itself, as well as $K L K 3$ and $U B E 2 C$, an androgen-independent AR target [6] (Figure 2B). Similar effects of the inhibitors on AR target gene expression in both the presence and absence of DHT were also observed in LNCaP-Abl CRPC cells (Supplementary Figure S2A). Notably, AR protein levels were also markedly reduced in androgen-depleted ACLYitreated cells, an effect that was magnified by the Combo (Figure 2C). ACLY silencing combined with an AR antagonist similarly suppressed AR levels (Supplementary Figure S4B).
To comprehensively evaluate the impact of the Combo on gene expression, we conducted RNAsequencing on C4-2 cells treated for 24 hours with ACLYi, ENZ, or the Combo under hormone-depleted conditions. Four major gene clusters were identified- 1) those suppressed by ACLYi and further suppressed by Combo (purple), 2) those suppressed by ENZ and further suppressed by Combo (red), 3) those induced by ACLYi and further enhanced by Combo (blue), and 4) those induced by both ACLYi and ENZ individually and further induced by Combo (yellow) (Figure 2D, Supplementary Table S1). Using Gene Set Enrichment Analysis (GSEA), we found that ACLYi suppressed expression of previously defined "acetyl-CoA-upregulated" genes and enriched "acetyl-CoA-downregulated" genes [17] (Supplementary Figure S2B). ACLYi alone also significantly suppressed "androgen-independent" genes (Supplementary Figure S2C), and combining ACLYi and ENZ further accentuated these effects, resulting in potent suppression of both "DHT-induced" and "androgen-independent" gene signatures [7] (Figure 2E).

\section{Combining ACLY and AR inhibitors induces ER stress}

To gain further insight into additional pathways that are regulated by the inhibitor Combo, we employed gene ontology analysis using the HOMER tool [46], focusing on the two largest clusters. Within the purple cluster, genes involved in cell cycle and DNA replication and repair predominated (Figure 3A, Supplementary Figure S3A), consistent with the observed reduction in proliferation with ACLYi or Combo. The blue cluster was strikingly defined by an endoplasmic reticulum (ER) stress signature (Figure 3B, Supplementary Figure S3B).

The unfolded protein response (UPR) is controlled by three sensors within the ER membrane: ATF6, IRE1, and PERK. Disturbances in lipid homeostasis or accumulation of unfolded proteins are detected within the ER lumen and mediate adaptive signaling and transcriptional responses to restore ER homeostasis. The UPR can also exert pro-apoptotic functions when ER stress is prolonged or unresolvable [47]. Notably, the AR differentially regulates UPR pathways, promoting the IRE1 arm while suppressing the PERK arm and its downstream pro-apoptotic outputs such as CHOP [48]. Among ER-stress signature genes strongly induced by the inhibitor Combo were ATF3, DDIT3 (CHOP) and CHOP targets $B B C 3$ (PUMA) and TRIB3 (Supplementary Figure S3B and Supplementary Table S1), which are implicated in stress-induced apoptosis [49-52]. CHOP is a transcriptional target of ATF4, a transcription factor that is translationally upregulated by the PERK-eIF $2 \alpha$ arm of the UPR [47]. Consistently, p-eIF2 $\alpha$ and ATF4 levels and target gene expression were elevated rapidly upon Combo treatment (Figure 3C, 3D). We also observed increased 
A.

Dihydrotestesterone (DHT)-treated

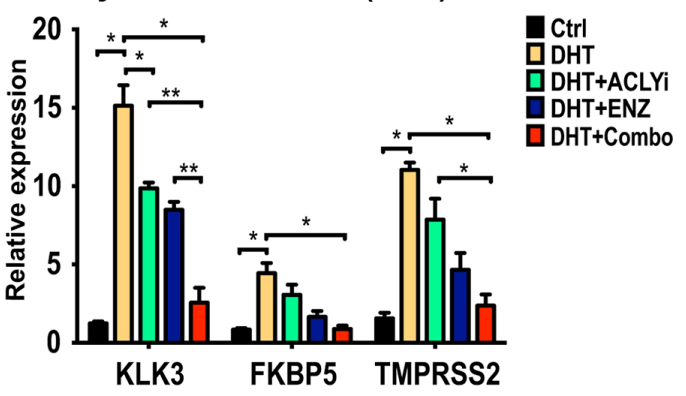

c.

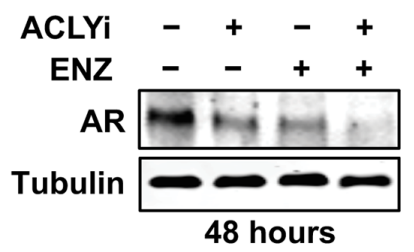

D.

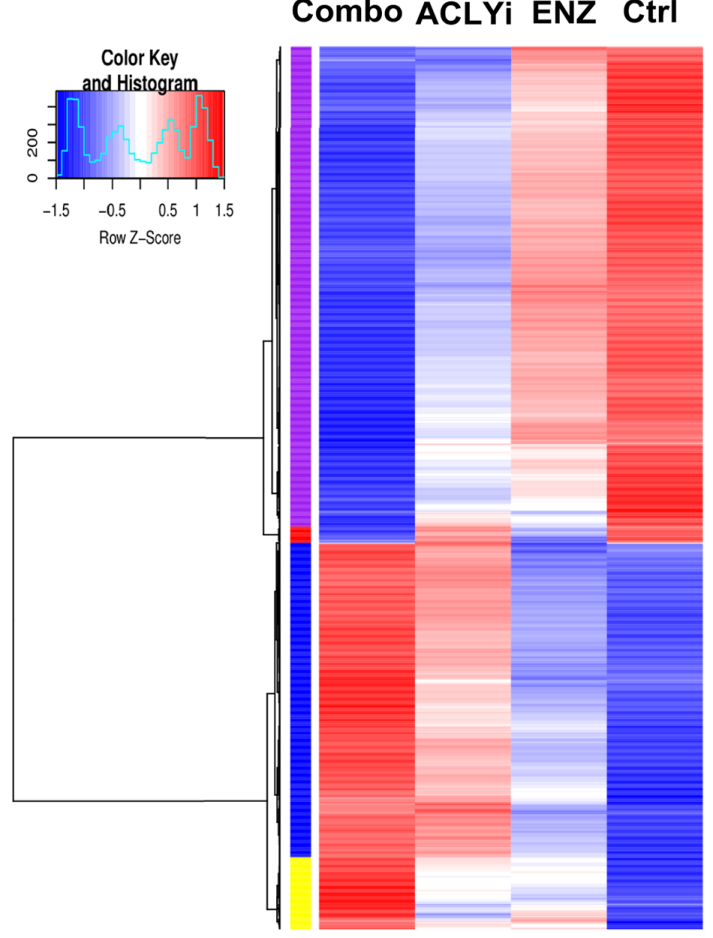

B.

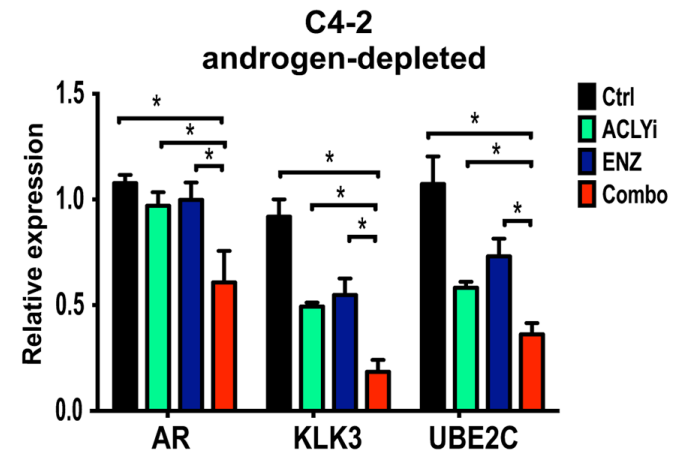

E.

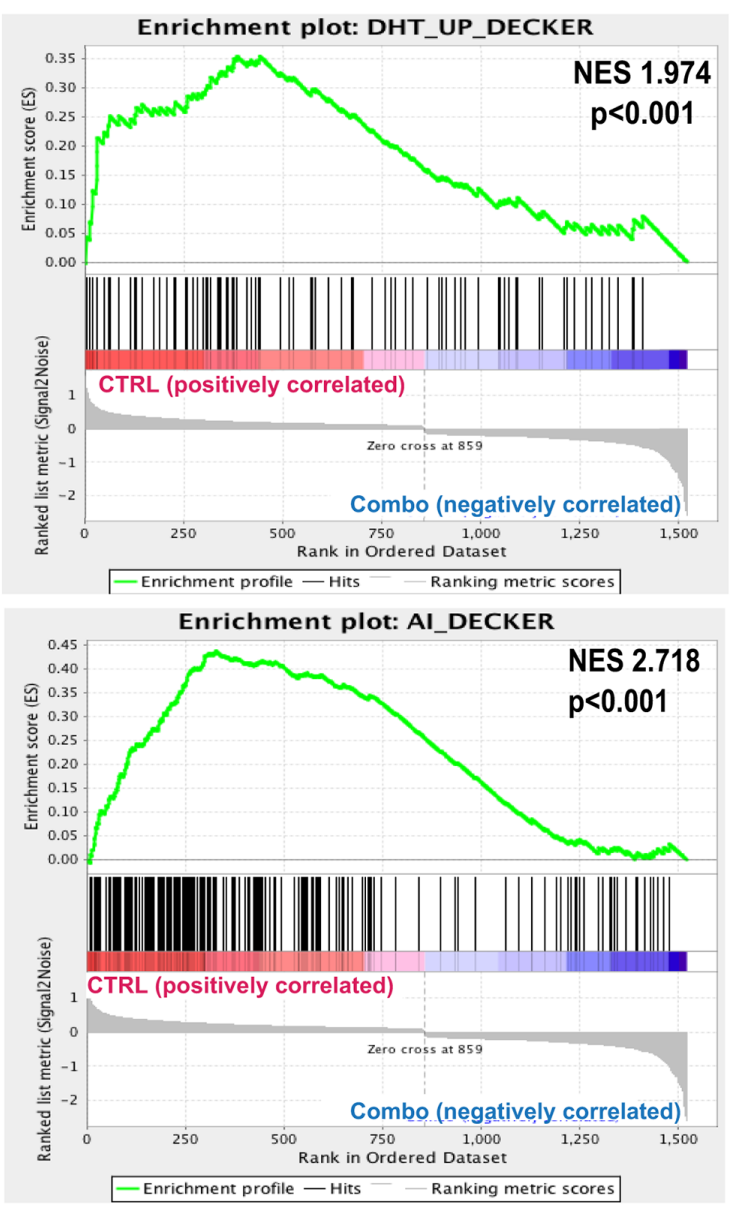

Figure 2: Combining ACLY and AR inhibitors suppresses AR target gene expression. A. C4-2 cells were cultured in androgen-depleted conditions for 24 hours and then treated with DHT $(10 \mathrm{nM}),+/$ - ACLYi $(10 \mu \mathrm{M}),+/$ - ENZ $(20 \mu \mathrm{M})$ for an additional 24 hours. Gene expression was analyzed by Q-RT-PCR and normalized to 18S rRNA. Combo denotes ACLYi + ENZ. B. C4-2 cells were cultured in androgen-depleted conditions for 24 hours and then treated +/- ACLYi $(10 \mu \mathrm{M})$, +/- ENZ $(20 \mu \mathrm{M})$ for an additional 24 hours. Gene expression was analyzed by Q-RT-PCR and normalized to B2M. C. Cells were treated with ACLYi or ENZ for 48 hours in androgen-depleted conditions and AR levels analyzed by Western blot. D. C4-2 cells in androgen-depleted conditions were treated with vehicle, ACLYi alone, ENZ alone, or the inhibitor Combo. Genes differentially expressed in any two comparisons (FDR $<0.0001$ ) were clustered and are represented in the heat map. See Supplementary Table S1 for associated gene list and cluster ID. E. Gene set enrichment analysis (GSEA) was used to test whether the "DHT-Up" and "Androgen Independent" gene signatures, as defined by Decker et al [7], were enriched in Ctrl vs. Combo-treated cells. Both of these gene sets were enriched in control C4-2 cells as compared to Combo-treated C4-2 cells. Normalized enrichment score (NES) and p-values are indicated. See Supplementary Figure S2 for comparisons between Ctrl vs. ACLYi alone. For all bar graphs, mean $+/-$ SEM of triplicates is graphed; *, $<<0.05 ; * *, p<0.01$ 

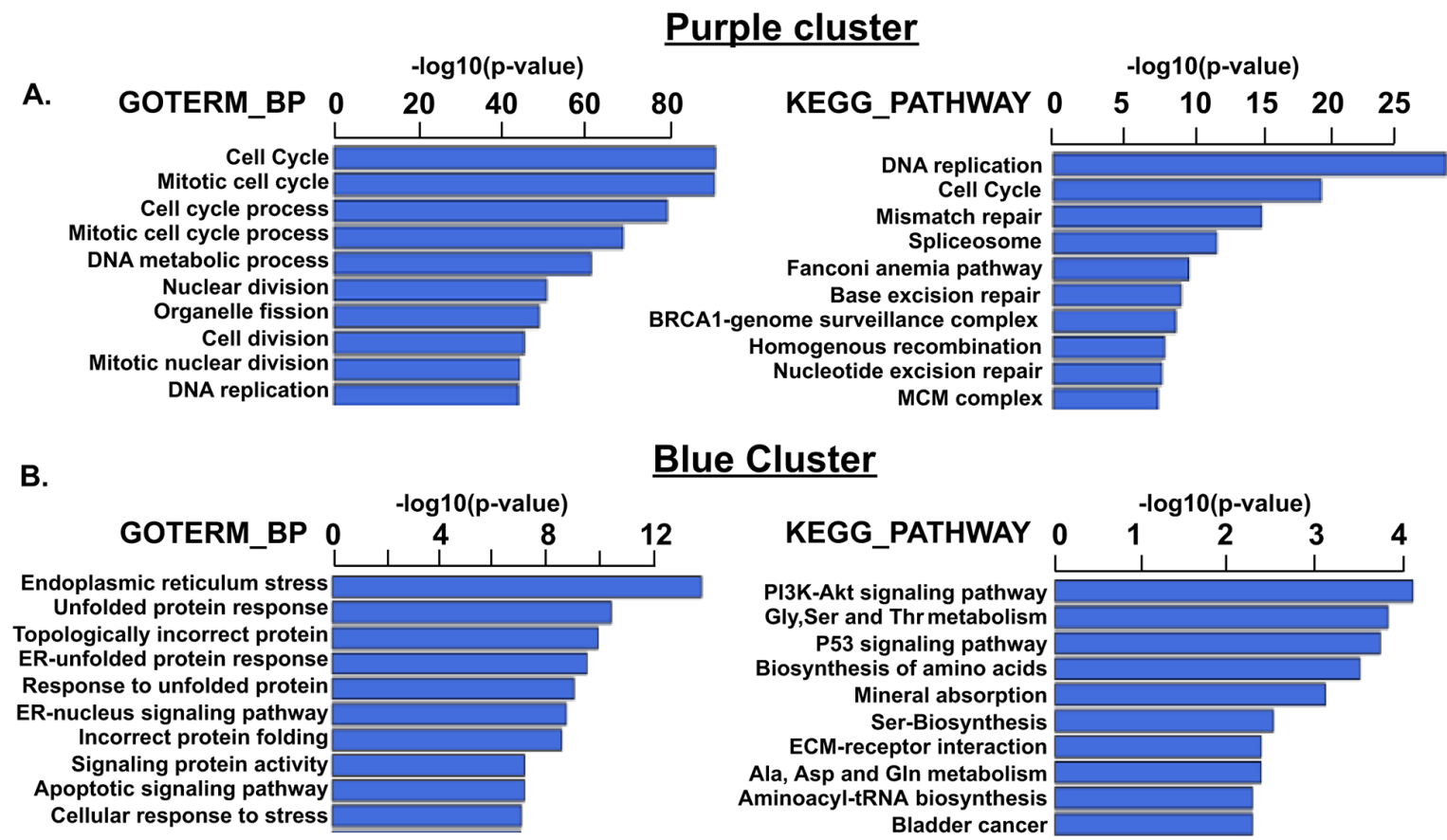

\section{Blue Cluster}

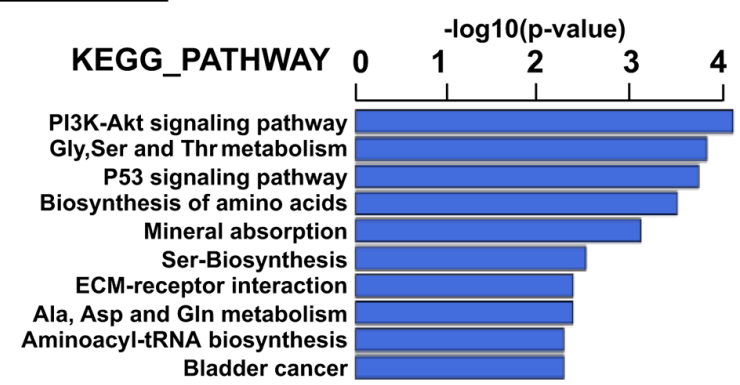

C.

D.
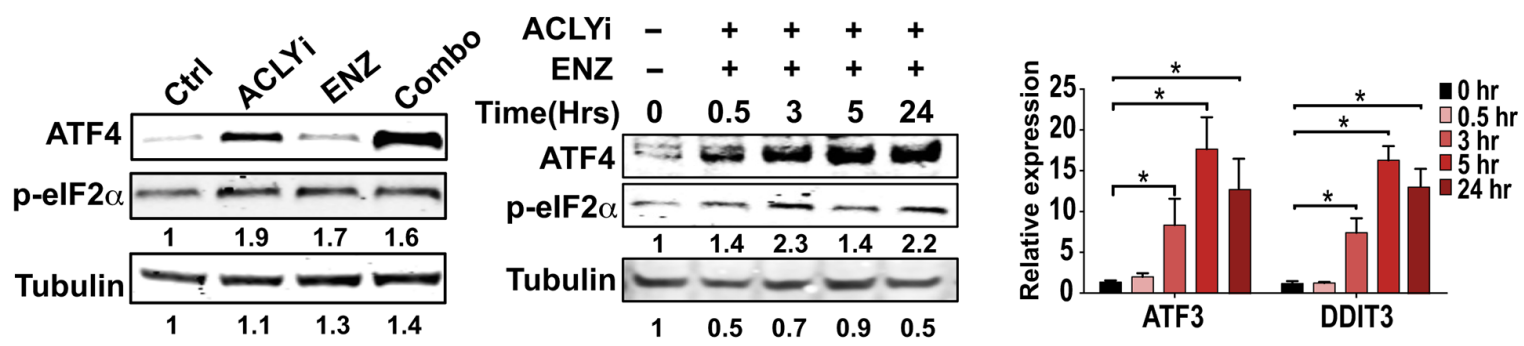

E.
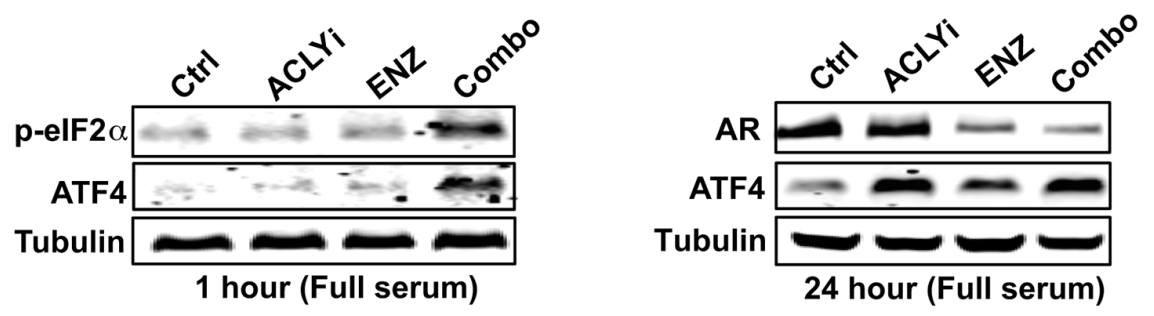

F.

$\begin{array}{rllllll}\text { ACLYi } & - & + & + & + & + & + \\ \text { ENZ } & - & + & + & + & + & + \\ \text { Time (Hours) } & 0 & 0.5 & 1.5 & 3 & 5 & 24 \\ \text { p-AKT-T308 } & - & & - & - & \vdots\end{array}$

G.

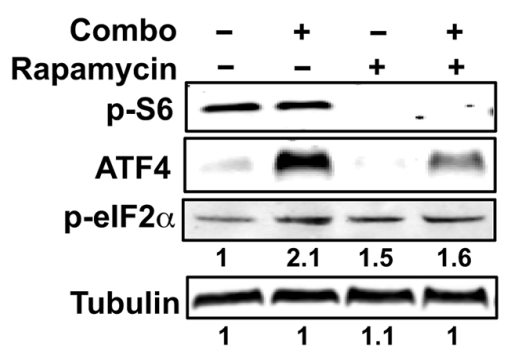

Figure 3: Combining ACLY and AR inhibitors induces endoplasmic reticulum stress. A, B. RNA-sequencing data was analyzed using the HOMER tool [46]. GOTERM_BP and KEGG_PATHWAY analyses are shown for the purple cluster (downregulated genes, A) and blue cluster (upregulated genes, B). C. C4-2 cells were treated with indicated inhibitors for 24 hours under androgen deprivation and analyzed by Western blot. D. C4-2 cells were treated with ACLYi + ENZ under androgen deprivation for indicated times and analyzed by Western blot and Q-RT-PCR. E. C4-2 cells were treated for 1 or 24 hours with indicated inhibitors in standard serum (not androgen depleted) and analyzed by Western blot. F. AKT phosphorylation was analyzed by Western blot after treating C4-2 cells as indicated under androgen deprivation. G. C4-2 cells were pre-treated for 1 hour with rapamycin, then treated with Combo for an additional hour and analyzed by Western blot. For all bar graphs, mean $+/-$ SEM of triplicates is graphed; *, $p<0.05$ 
p-eIF2 $\alpha$ and ATF4 levels with Combo treatment when cells were cultured in standard (non-hormone-depleted) FBS (Figure 3E).

Ample evidence in the literature indicates that inhibition of fatty acid synthesis can induce ER stress, particularly if environmental lipids are scarce [42, 43, 53]. Indeed, ACLYi alone induced ATF4 and expression of some ER stress genes; these responses were magnified when ACLYi was combined with ENZ (Figure 3C and 3E, Supplementary Figure S3B, and Supplementary Table $\mathrm{S} 1)$. Coordination of lipid and protein synthesis is vital for ER homeostasis, and hyper-activation of the PI3K-AKTmTORC1 pathway drives dependence on de novo lipid synthesis for ER homeostasis [42-44, 54, 55]. Notably, a PI3K-AKT signaling pathway gene signature is induced upon Combo treatment (Figure 3B), consistent with prior studies demonstrating that the AR pathway exerts an inhibitory influence over PI3K-AKT pathway [40, 41]. pAKT levels were indeed elevated after Combo treatment (Figure 3F), although signaling downstream of mTORC1 was not similarly elevated (Supplementary Figure $\mathrm{S} 3 \mathrm{C}$ ), likely due to repression by AMPK (see below). Nevertheless, inhibition of mTORC1 using rapamycin reduced Combo-mediated induction of ATF4 (Figure 3G). Thus, the pro-apoptotic effects of combining ACLY and AR inhibitors could result at least in part from ER stress.

\section{Concurrent inhibition of ACLY and AR promotes AMPK activation}

While analyzing the signaling responses to the drug treatments, we noticed that AMPK was potently activated (as assessed by phosphorylation of AMPK and its target ACC1) upon ACLYi or Combo treatment, and that this activation correlated closely with suppression of AR protein levels (Figure 4A and Supplementary Figure S4A). AMPK activation and AR suppression were also observed when shRNA targeting ACLY was used in conjunction with AR antagonism (Supplementary Figure S4B). Recent studies have shown that AMPK activation suppresses AR levels and inhibits prostate cancer cell proliferation and tumor growth $[32,56,57]$, and that this response is magnified in the presence of an AR antagonist [32, 57], similar to our observations with ACLY inhibition in this study. Consistently, the AMPK activator AICAR also sensitized C4-2 cells to ENZ (Supplementary Figure S4C).

We thus investigated the cause of AMPK activation in Combo-treated cells. AMPK activation occurred rapidly upon administration of the Combo, detectable within 30 min (Figure 4B). Although AMPK can be activated in response to diverse stress conditions, the AMP/ATP ratio was also rapidly elevated and sustained following Combo treatment, indicating that energetic stress could be the cause of AMPK activation (Figure 5D). AR protein levels and target gene changes appeared later, beginning to decline about 5 hours following Combo treatment
(Figure 4B). Prior studies have demonstrated that AMPK activation inhibits the AR by decreasing its mRNA and protein levels and/or by impairing its nuclear localization $[32,56,58]$. In this context, the effects of the Combo appear to be predominantly on AR levels, since protein levels were drastically reduced but nuclear localization minimally impacted (Supplementary Figure S5A). Together, these data indicate that combined inhibition of ACLY and AR under hormone-depleted conditions rapidly results in energetic stress and AMPK activation, thereby further reducing total AR levels and promoting cell death.

To determine if Combo treatment impacted energyproducing metabolic fluxes, we examined its effects on glucose and glutamine uptake and lactate production. The results showed that Combo treatment produced a marked increase in glucose consumption and lactate production and little change in glutamine consumption (Figure 4C). Glucose oxidation, as assessed by labeling of TCA metabolites from $\left[\mathrm{U}-{ }^{13} \mathrm{C}\right]$-glucose, was only minimally changed in the presence of the Combo (Figure 4D). Moreover, there was no significant change in complex I- or complex I- and II-dependent oxidative phosphorylation, nor in complex II- or complex I- and II-dependent maximal respiration (Figure 4E). Thus, surprisingly, cells experience energetic stress despite having abundant access to and ability to uptake and utilize two major carbon sources, glucose and glutamine.

\section{Fatty acid supplementation restores energetic homeostasis in cells treated with ACLY and AR inhibitors}

To gain insight into the mechanism causing energetic stress, we next attempted to rescue viability and proliferation in the presence of the Combo using supplementation of a panel of metabolites, including fatty acids (50:50 palmitic acid (PA): oleic acid (OA), BSA conjugated), mevalonate, sodium pyruvate, dimethyl $\alpha$-ketoglutarate, and sodium acetate. Of these metabolites, only fatty acids potently rescued cell number (Figure 5A). BSA alone did not rescue cell number, but both PA and OA individually improved viability (Supplementary Figure S5B). Fatty acid supplementation also reversed the proliferation impairment observed with ACLYi treatment (Supplementary Figure S5C). Exposure to fatty acids prevented Combo- mediated AMPK activation and rescued AR levels in both C4-2 and LNCaP-Abl cells (Figure 5B and Supplementary Figures 5A, 5D). $A R$ mRNA and AR target genes were also significantly rescued by fatty acid supplementation (Figure 5C and Supplementary Figure S5E). Additionally, the elevated AMP/ATP ratio was reversed by exogenous fatty acids (Figure 5D).

Prior studies have demonstrated that while fatty acid oxidation (FAO) is conducted minimally in many cancer cells [59], it is important in prostate cancer cells [60-62]. We thus hypothesized that fatty acids rescue 
viability and suppress AMPK activation in the Combotreated cells through ATP production via $\beta$-oxidation. To test this possibility, we conducted stable isotope labeling experiments using either $\left[\mathrm{U}-{ }^{13} \mathrm{C}\right]$-glucose [with unlabeled 50:50 palmitic acid (PA): oleic acid (OA) present] or a 50:50 mix of $\left[\mathrm{U}-{ }^{13} \mathrm{C}\right]-\mathrm{PA}:\left[\mathrm{U}-{ }^{13} \mathrm{C}\right]-\mathrm{OA}$ (with unlabeled glucose present), and examined enrichment in TCA cycle intermediates. After 6 hours of labeling, both glucose and fatty acid carbon were detectable in TCA cycle intermediates in control-treated cells (Figure 5E). In control cells, citrate $\mathrm{m}+2$ (citrate enriched with two carbon-13 atoms) accounted for $\sim 15 \%$ of the total citrate pool in the ${ }^{13} \mathrm{C}$-glucose-labeled cells and $\sim 7 \%$ of the pool in ${ }^{13} \mathrm{C}$-fatty acid-labeled cells. However, Combo treatment markedly reduced the oxidation of fatty acids in the TCA cycle while increasing the oxidation of glucose (Figure 5E). Thus, FAO does not appear to be central to the mechanism through which fatty acids rescue energetic stress in this context.
A.

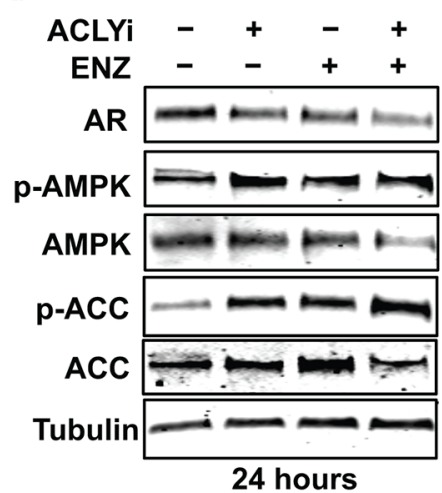

B.

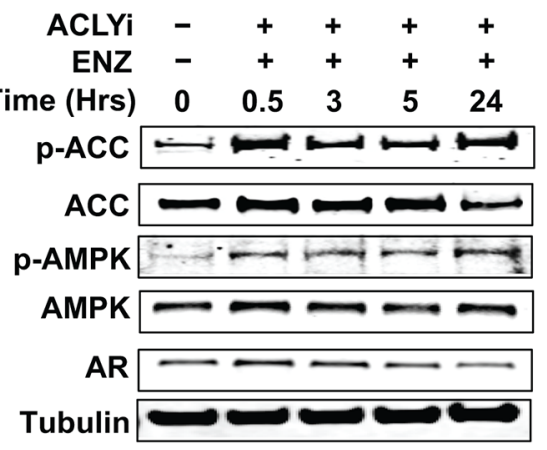

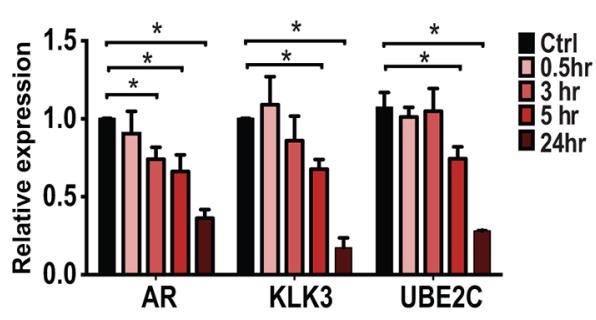

E.

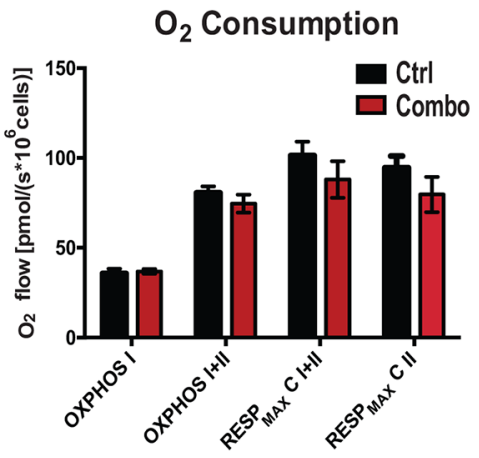

Malate

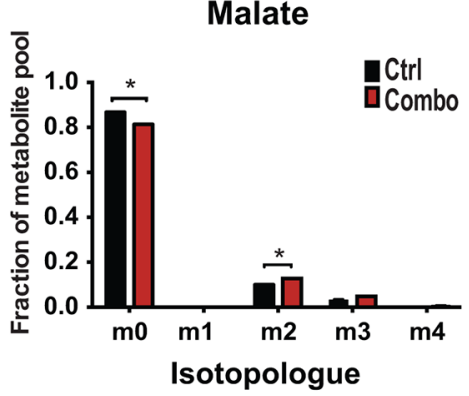

Figure 4: ACLY and AR inhibition promotes AMPK activation without suppressing glucose uptake or oxidation. A. C4-2 cells were treated as indicated for 24 hours under androgen deprivation and analyzed by Western blot. B. C4-2 cells were treated with Combo over a time-course and analyzed by Western blot and Q-RT-PCR. C. Consumption of glucose and glutamine from media and production of lactate were analyzed from control and Combo-treated C4-2 cells using a YSI-7100 Bioanalyzer. D. [U- $\left.{ }^{13} \mathrm{C}\right]$-glucose labeling of C4-2 cells was conducted, +/- Combo, for 3 hours. Labeling was initiated at the same time as application of the inhibitors. Enrichment in TCA cycle intermediates was assessed. E. Oxygen consumption was measured in androgen-depleted C4-2 cells, treated $+/-$ Combo for 24 hours. For all bar graphs, mean $+/-$ SEM of triplicates is graphed; *, $p<0.05$. 
A.

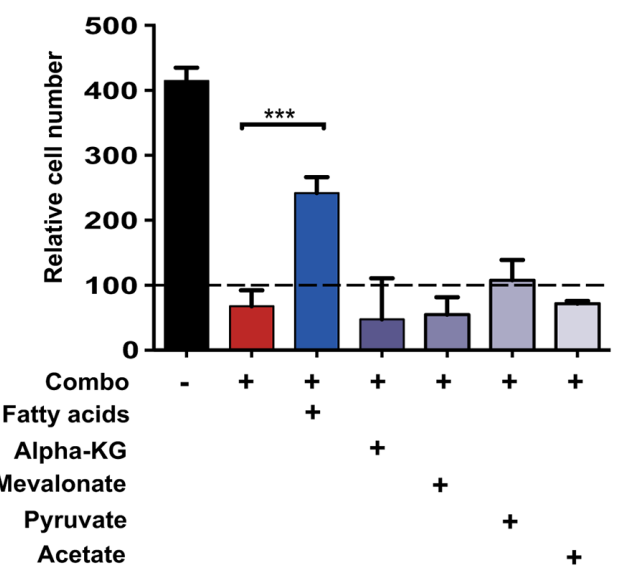

c.

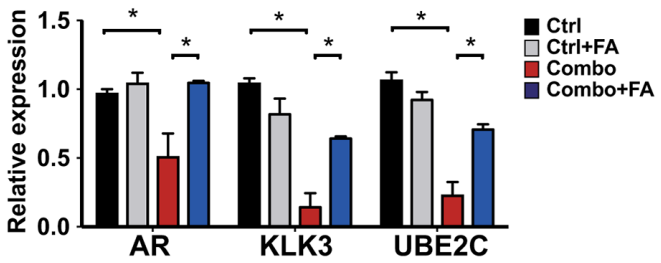

B.

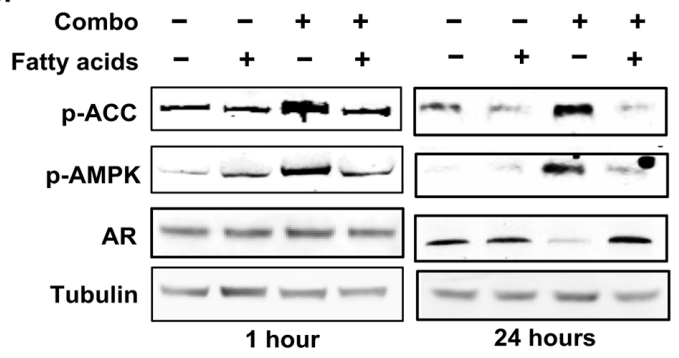

D.

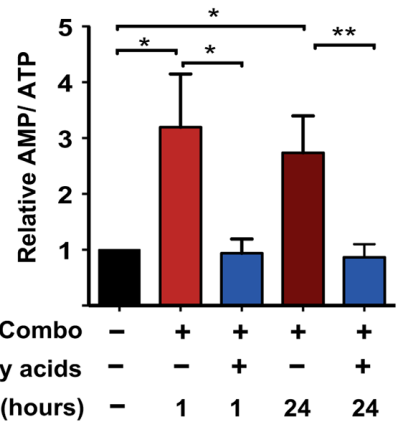

E.
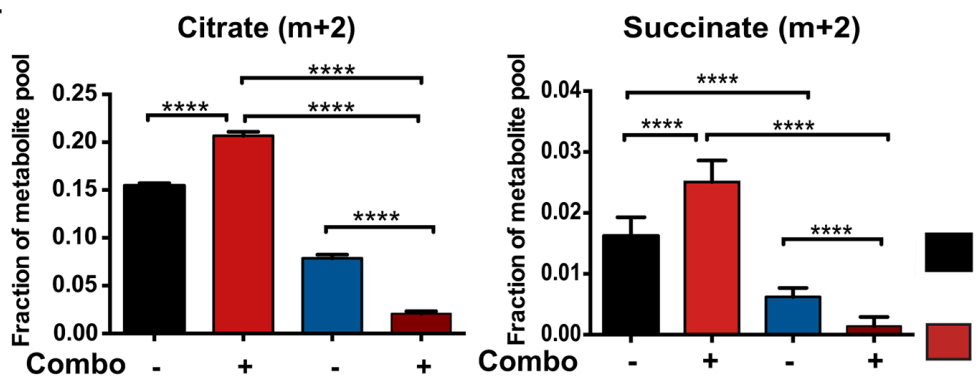

${ }^{13} \mathrm{C}$-Glc (10 mM) +unlabeled

PA:OA $(75 \mu \mathrm{M})$, Ctrl

${ }^{13} \mathrm{C}$-GIc (10 mM) +unlabeled PA:OA $(75 \mu \mathrm{M})$, Combo
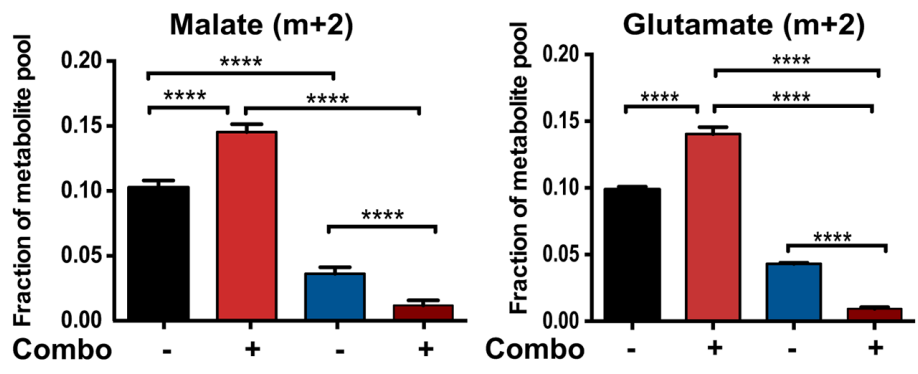

Unlabeled Glc $(10 \mathrm{mM})+$

${ }^{13} \mathrm{C}-\mathrm{PA}:{ }^{13} \mathrm{C}-\mathrm{OA}(75 \mu \mathrm{M})$, Ctrl

Unlabeled Glc (10 mM) +

${ }^{13} \mathrm{C}$-PA: ${ }^{13} \mathrm{C}$-OA(75 $\left.\mu \mathrm{M}\right)$, Combo

Figure 5: Fatty acid supplementation restores energetic homeostasis in ACLY/ AR inhibitor-treated cells, without directly supporting ATP production through $\boldsymbol{\beta}$-oxidation. A. C4-2 cells in androgen-depleted conditions were treated with vehicle, Combo alone, or Combo plus indicated metabolites including fatty acids (75 $\mu \mathrm{M}, 50: 50$ Palmitic acid (PA): Oleic acid (OA), BSA conjugated), dimethyl- $\alpha-\mathrm{KG}(1 \mathrm{mM})$, mevalonate $(100 \mu \mathrm{M})$, Na-pyruvate $(5 \mathrm{mM})$, acetate $(500 \mu \mathrm{M})$ for 72 hours. After 72 hours, viable cells were counted using trypan blue exclusion and normalized to staring cell number, set to 100 . B. Immunoblotting was carried out on C4-2 cell lysates treated with vehicle or Combo, +/- fatty acids for 1 hour or 24 hours. C. Gene expression in C4-2 cells treated with vehicle or Combo, +/- fatty acids for 24 hours. D. C4-2 cells were treated with Combo $+/-$ fatty acids for 1 hour or 24 hours. AMP and ATP were measured by HPLC. Experiment was repeated 4 times, with relative AMP/ATP ratio in untreated cells for each experiment set to 1. 2-tailed paired t-test was conducted. E. To assess the relative contribution of glucose and fatty acids to TCA cycle intermediates in control and Combo-treated cells, labeling studies were conducted. Cells were labeled either with $10 \mathrm{mM}\left[\mathrm{U}-{ }^{13} \mathrm{C}\right]$-glucose $+75 \mu \mathrm{M}$ unlabeled PA: OA or with $75 \mu \mathrm{M}\left[\mathrm{U}-{ }^{13} \mathrm{C}\right]-\mathrm{PA}:\left[\mathrm{U}-{ }^{13} \mathrm{C}\right]-\mathrm{OA}+10 \mathrm{mM}$ unlabeled glucose. Cells were treated $+/-$ Combo concurrent with initiation of labeling, and metabolite enrichment was analyzed after 6 hours. Unless otherwise indicated, mean $+/-$ SEM of triplicates is graphed; *, $<0.05 ; * *$, $\mathrm{p}<0.01, * * * *, \mathrm{p}<0.0001$. 


\section{Fatty acids rescue ER homeostasis in combo- treated cells}

Since these data suggested that fatty acids do not rescue Combo-treated cells through their direct contribution to mitochondrial ATP production, we next considered the possibility that fatty acids might relieve excess ATP consumption. Protein synthesis and folding and maintenance of ER function are highly energy demanding [63]. As shown in Figure 3, Combo treatment promotes both AKT activation and ER stress. If fatty acids support energetic homeostasis by suppressing ER stress, this could also explain why fatty acids, but not other substrates such as $\alpha \mathrm{KG}$, pyruvate, or acetate, rescued proliferation (Figure 5A). Among genes induced by the drug Combo is ENTPD5 (Figure 6A and Supplementary Table S1), an ER UDPase that activates a cycle of ATP hydrolysis to promote protein glycosylation and folding in AKT-activated cells, in order to promote ER homeostasis $[64,65]$. Notably, ENTPD5 is reported to play a major role in ATP consumption and thus, by alleviating allosteric inhibition of PFK1 by ATP, promotes glycolysis $[64,66]$. Activation of ENTPD5 is consistent with our findings that the Combo treatment promotes increased glucose consumption and lactate production (Figure 4C), while also increasing the AMP/ATP ratio (Figure 5D). Silencing of ENTPD5 partially suppressed Combo-mediated AMPK activation (Figure 6B), suggesting that ENTPD5 contributes to energetic stress upon Combo treatment, but likely is not the only relevant factor.

We next tested whether fatty acid supplementation could prevent ER stress induction upon Combo treatment. Fatty acid supplementation indeed entirely reversed the effects of Combo treatment on ATF4 levels, as well as ATF4 and CHOP target genes at all time points tested (Figure 6C, 6D and Supplementary Figure S6). Transcriptional targets downstream of IRE1 and ATF6 were also suppressed by fatty acid supplementation (Supplementary Figures S6, S7). Finally, both proliferation and viability were significantly rescued upon fatty acid supplementation (Figure 6E, 6F).

Together these data point to the importance of ACLY function for maintaining ER and energetic homeostasis in CRPC cells. ER homeostasis prevents aberrant AMPK activation, which can suppress the AR [32, 56, 58]. Thus, an ACLY-AMPK-AR feedback loop sustains AR levels in CRPC cells and may contribute to resistance to AR antagonists. If such a feedback loop is relevant in human tumors in vivo, a relationship between expression of fatty acid metabolism genes and the AR might be anticipated. To investigate this link, we made use of two recently published human prostate cancer datasets, a prostate adenocarcinoma dataset from TCGA and a metastatic prostate cancer dataset from SU2C/PCF [16, 67]. We found that $A R$ mRNA positively correlated with fatty acid synthesis ( $A C L Y, A C A C A, F A S N)$ genes in both datasets
(Figure 6G). Together, the findings of this study suggest that fatty acid metabolism plays a key role in coordinating ER and energetic homeostasis in prostate cancer cells, and that ER stress and AMPK activation caused by concurrent ACLY and AR inhibition leads to enhanced AR suppression, growth inhibition, and cell death.

\section{DISCUSSION}

In this study, we report that inhibiting ACLY sensitizes CRPC cells to AR antagonism. Concurrent inhibition of ACLY and AR results in both inhibition of proliferation and induction of apoptosis, particularly in androgen-depleted conditions. The inhibitor Combo induces energetic stress and AMPK activation, which suppresses AR levels. Thus, this study points to an ACLYAMPK-AR network that could potentially be targeted to increase the efficacy of current AR-targeted therapies, by impacting metabolic dependencies of prostate cancer cells.

The data point to a model in which $\mathrm{AR}+$ prostate cancer cells coordinate cell metabolism and signaling to support the demands of oncogenic signaling (Figure 7A). Upon AR inhibition, AKT is hyper-activated due to alleviation of AR's feedback inhibition on AKT [40, 41]. Elevated AKT activation promotes increased reliance on ACLY-dependent fatty acid synthesis for ER homeostasis [18]; thus, when ACLY is inhibited in this context, an ER stress response is engaged and cannot be resolved. In the context of AKT activation and ER stress, the ER UDPase ENTPD5 is activated to promote protein glycosylation, driving excessive ATP consumption [64, 65]. As the AMP/ATP ratio rises, AMPK is turned on, driving further suppression of the AR. Thus, by sustaining ER homeostasis, fatty acid metabolism plays a crucial roleparticularly in PTEN null prostate tumors- in maintaining energetic homeostasis and AR levels (Figure 7B). Since $49 \%$ of metastatic prostate cancer patients exhibit PI3K/ AKT pathway alterations [16], these results are suggestive of possible new therapeutic strategies for these patients, although this requires investigation in vivo.

A prediction of the findings of this study is that compounds targeting other nodes in the ACLY-AMPK-AR network could also be combined with AR inhibition for therapeutic benefit. Consistent with this possibility, both metformin, which activates AMPK and also inhibits fatty acid synthesis in an AMPK-independent manner [68, 69], and a novel AMPK activator (MT 63-78) led to improved anti-tumor effects when combined with AR antagonists $[32,58]$. Fatty acid synthesis inhibition warrants further investigation in an in vivo context, since tumors frequently outstrip the vasculature and must therefore synthesize fatty acids and other macromolecules to grow in a nutrientrestricted environment [44]. Moreover, ACLY inhibition produces lipid-lowering effects $[45,70,71]$, potentially further reducing lipid availability to tumors. Direct AMPK activation is another attractive option, and metformin is 
A.

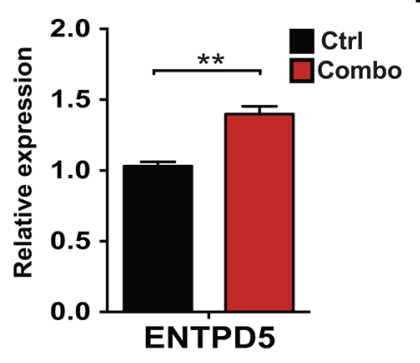

B.

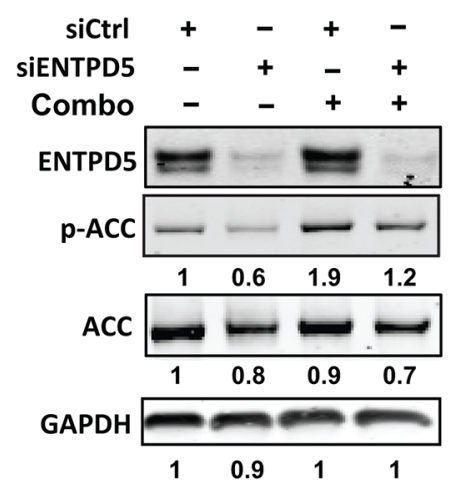

C.

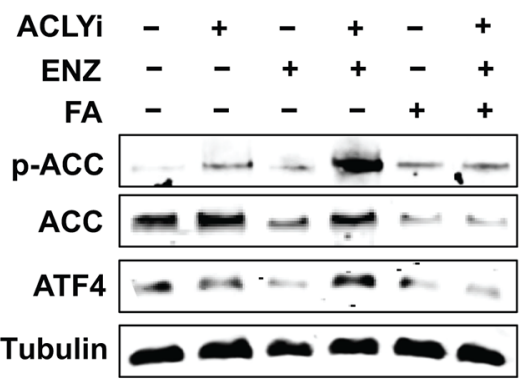

D.
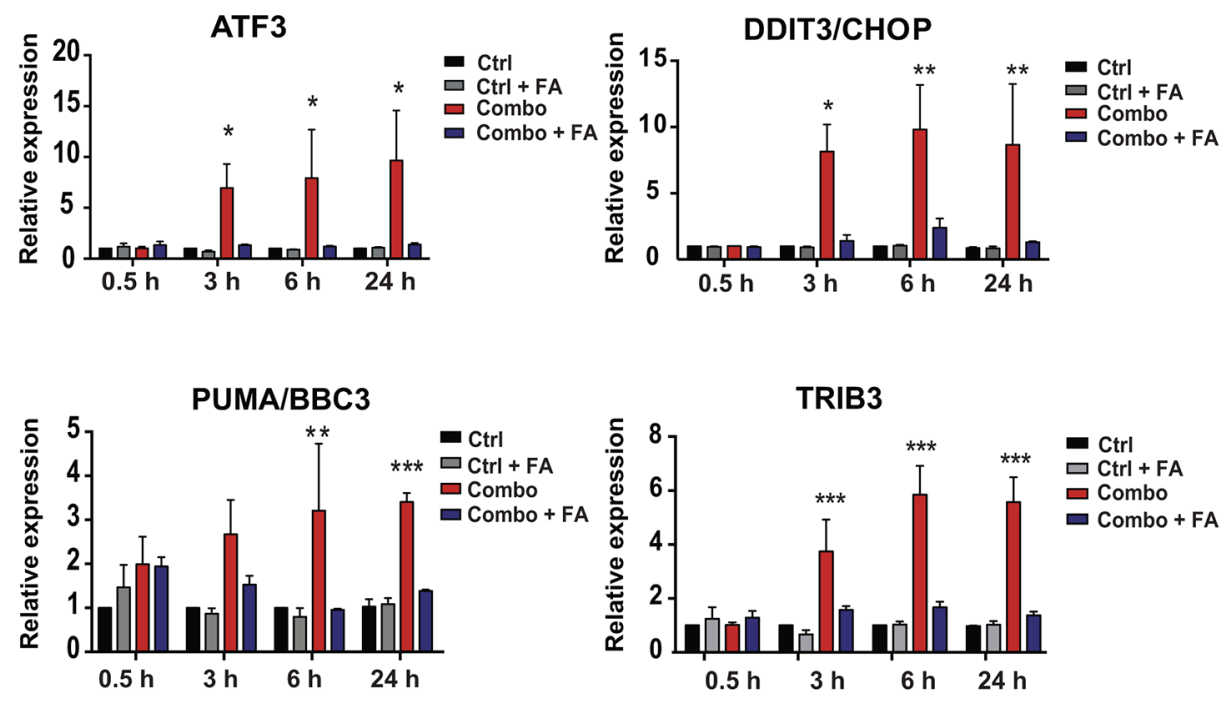

E.

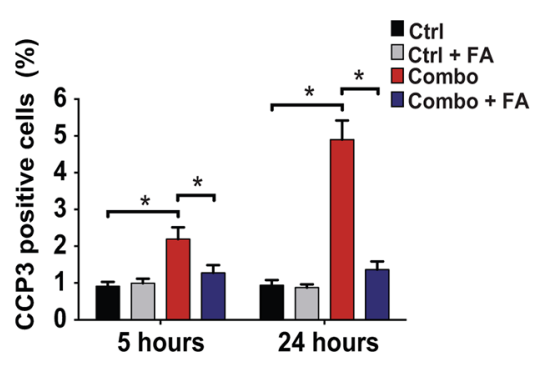

F.

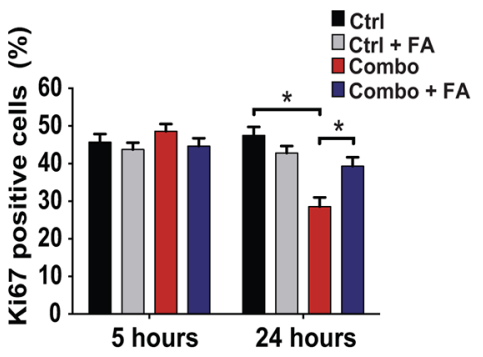

G.

AR correlations: FA metabolism genes

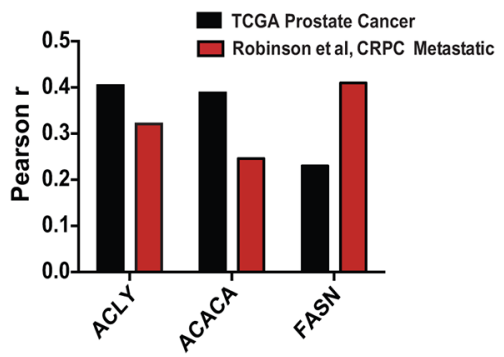

Figure 6: Exogenous fatty acids prevent ER stress and support cell proliferation and viability during treatment with ACLY and AR inhibitors. A. ENTPD5 gene expression analyzed by Q-RT-PCR after 24 hours Combo treatment in androgen-depleted C4-2 cells. B. siRNA targeting ENTPD5 or a non-silencing control siRNA were transfected into C4-2 cells, and after 96 hours, cells were treated +/- Combo for an additional 24 hours before analyzing by Western blot. C. LNCaP-Abl cells were treated with indicated inhibitors, $+/-75 \mu \mathrm{M}$ fatty acids (50:50 PA:OA). D. Gene expression was analyzed by Q-RT-PCR at indicated time points, $+/-$ Combo, $+/-75 \mu \mathrm{M}$ fatty acids (50:50 PA:OA). E, F. At indicated time points following Combo treatment, $+/-$ fatty acids, apoptotic marker CCP3 (E) or proliferation marker Ki67 (F) were assessed. For all bar graphs, mean +/- SEM of triplicates is graphed; *, p $<0.05$; **, p $<0.01, * * *, p<0.001$. G. Using the www.cBioportal.org resource [81, 82], AR mRNA levels were tested for correlation with the indicated genes in the prostate cancer TCGA Prostate Adenocarcinoma (mRNA expression, RNA-Seq V2 RSEM) and the Metastatic Prostate Cancer, SU2C/PCF Dream Team (mRNA Expression/ polyA, RNA-Seq RPKM) [16, 67]. The key indicates the strength of the correlation, as assessed by Pearson's r. For TCGA data, with $n=333$, all correlations are significant to $\mathrm{p}<0.0001$. For the metastatic dataset, with $\mathrm{n}=150$, ACLY and FASN correlations are significant to $\mathrm{p}<0.0001$; ACACA correlation is significant to $\mathrm{p}<0.01$. 


\section{A. Growing prostate tumor}
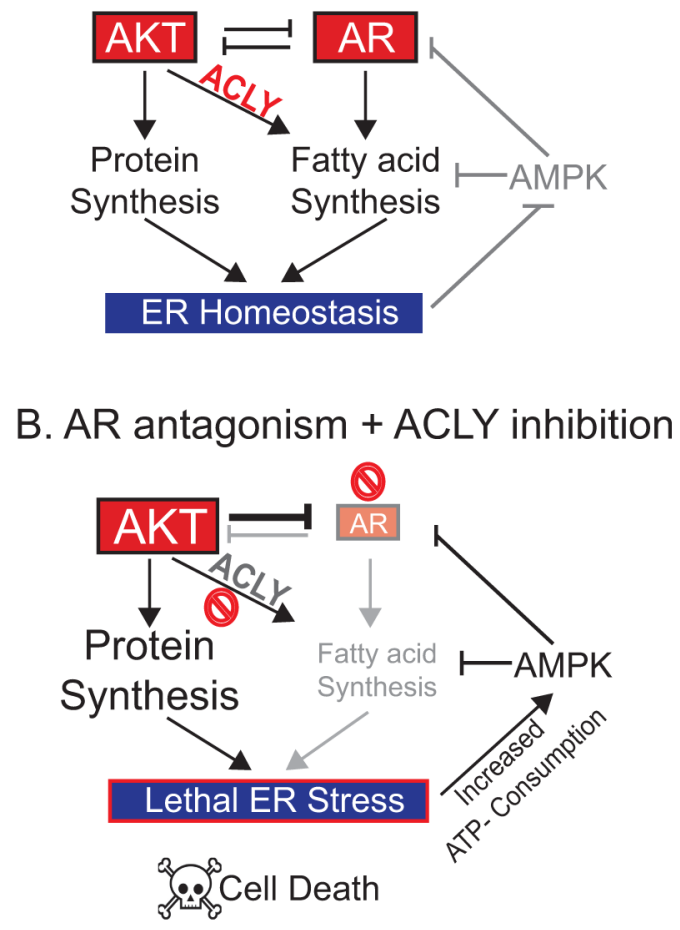

Figure 7: Model: An ACLY-AMPK-AR network sustains ER homeostasis, AR levels, and cell survival in prostate cancer. A. In proliferating PTEN null prostate cancer cells, the demands of oncogenic signaling are met by metabolic rewiring including de novo fatty acid synthesis, which supports endoplasmic reticulum (ER) homeostasis and suppresses AMPK activation to promote proliferation. B. Upon inhibition of AR, AKT is hyper-activated, placing increased demand on the de novo fatty acid synthesis pathways to support ER homeostasis. If ACLY and hence fatty acid synthesis is also inhibited, unresolvable ER stress ensues. In the PTEN null context, this can trigger ENTPD5 activation, excessive ATP consumption, and AMPK activation. AR can then be further suppressed by AMPK and AKT, two negative regulators. The combination of AR suppression and pro-apoptotic ER stress may induce cell death. Thus, the ACLYAMPK-AR feedback loop can be exploited to sensitize CRPC cells to AR antagonism.

appealing in this regard, since it is both safe for patients and the proof-of-concept that metformin and ENZ are effective in suppressing growth of mouse prostate cancer xenograft tumors has been demonstrated $[58,72]$. Intriguingly, a novel dual function ACLY inhibitor/ AMPK activator has entered clinical trials for metabolic diseases [70]; such a compound could be attractive to test for efficacy in prostate cancer along with an AR antagonist.

Although the dominant effect of ACLY inhibition observed in this study is on fatty acid metabolism, additional effects on acetylation are not ruled out. In particular, restricted histone acetylation has been shown to inhibit the accessibility of chromatin to the AR by attenuating recruitment of the pioneering factor GATA2 [39]. The AR itself is also acetylated, a modification that increases its stability [73]. Since ACLY inhibition on its own has some effect on suppressing protein but not mRNA levels of AR (Figures $2 \mathrm{~B}$ and 2C), it may be of interest to test a role for ACLY in regulating AR acetylation in the future.

In summary, our data points to the crucial role of ACLY-dependent fatty acid synthesis in coordinating endoplasmic reticulum and energetic homeostasis in prostate cancer cells. By repressing aberrant AMPK activation, fatty acid metabolism thus helps to sustain AR activity, cell survival and proliferation. These studies provide a rationale for further testing of ACLY inhibitors or AMPK activators, particularly in conjunction with AR antagonists, for treatment of CRPC.

\section{MATERIALS AND METHODS}

\section{Reagents and cell lines}

C4-2 cells were a gift of $\mathrm{M}$. Kazanietz, University of Pennsylvania. LNCaP-Abl cells were a gift of $\mathrm{Z}$. Culig, Innsbruck Medical University. Prostate cancer cell lines LNCaP, PC-3, C4-2, and LNCaP-Abl were maintained in RPMI + 10\% FBS 2 mM L-Gln. 3T3L1 cells were cultured in DMEM $+10 \%$ FBS. All cell lines were confirmed to be mycoplasma-free. Androgen depletion experiments were carried out in phenol-redfree RPMI $+5 \%$ charcoal-dextran-treated (CDT) serum $+2 \mathrm{mM}$ L-Gln. For all androgen-deprivation experiments, 
cells were placed into CDT conditions for 24 hours prior to the addition of treatments. ACLY-inhibitors (BMS303141 and SB-204990), Bicalutamide, and Enzalutamide (ENZ) were purchased from Tocris (\#4609 and 4962), Sigma (\#B9061) and Toronto Research Chemicals (\#M199800), respectively. ACLY shRNA in pGipZ vector were purchased from Dharmacon (V2LHS_94212, \#12; V3LHS_395677, \#77). siRNA for ENTPD5 was Dharmacon SMARTpool (L-011235-00-0005).

\section{Immunoblotting}

Cells were lysed in RIPA buffer, in the presence of phosphatase and protease inhibitors and samples were run on NuPage SDS-PAGE gels. The ACLY antibody has been previously described [17]. Commercial antibodies used are listed below.

\begin{tabular}{lcc}
\hline $\begin{array}{l}\text { Antibody } \\
\text { name }\end{array}$ & Company & $\begin{array}{c}\text { Catalogue } \\
\text { number }\end{array}$ \\
\hline p-AMPK(T-172) & Cell Signaling & 2535 \\
Total AMPK & Cell Signaling & 2532 \\
Total AKT & Cell Signaling & 9272 \\
p-AKT (Thr308) & Cell Signaling & 9275 \\
p-AKT (Ser473) & Cell Signaling & 4060 \\
p-ACC & Cell Signaling & 3661 \\
Total ACC & Cell Signaling & 3676 \\
ATF4 & Cell Signaling & 11815 \\
p-eIF2 $\alpha$ & Cell Signaling & 3597 \\
AR(N-20) & SantaCruz & sc-816 \\
ENTPD5 & Biotechnology & Abcam \\
\hline
\end{tabular}

\section{YSI metabolite measurements}

Cells were seeded in CDT-RPMI in 6 well plates with $3 \times 10^{5}$ cells/well for 24 hours and treated as indicated for an additional 24 hours. Medium was collected at the end of the 24 hours, and glucose, glutamine, and lactate in supernatants were analyzed using a YSI-7100 Bioanalyzer, as previously described [74].

\section{${ }^{13} \mathrm{C}$-glucose labeling and GC-MS metabolite measurements}

For ${ }^{13} \mathrm{C}$-glucose labeling experiment in Figure 4, $4 \times 10^{6} \mathrm{C} 4-2$ cells were seeded in $10 \mathrm{~cm}$ dishes in CDTRPMI medium overnight. Each culture was then washed with PBS. CDT-RPMI containing $5 \mathrm{mM}\left[\mathrm{U}-{ }^{13} \mathrm{C}\right]$-glucose and no un-enriched glucose was added to the cultures for 3 hours either with or without Combo. At the end of the 3-hour period, metabolites were extracted as follows. Acidified cold methanol solution $(2.7 \mathrm{ml}$ of methanol, $30 \mu \mathrm{L}$ of $0.1 \mathrm{M} \mathrm{HCl}$ and $270 \mu \mathrm{L}$ water) was added with nor-leucine as an internal control. Nor-valine was also added to medium alone for comparison and stored. Cells were collected using a cell scraper and sonicated on a Branson Sonifior 250, at a power setting of 2.5 and a duty cycle of $20 \%$ for 30 seconds. The samples were centrifuged at $8,000 \mathrm{rpm}$ at $4^{\circ} \mathrm{C}$ for $10 \mathrm{~min}$. The metabolite-containing supernatant was evaporated under nitrogen at $40^{\circ} \mathrm{C}$. $100 \mu \mathrm{l}$ of N-tertbutyldimethylsilyl$\mathrm{N}$-methyltrifluoroacetamide (MTBSTFA) and $100 \mu \mathrm{l}$ of acetonitrile were added to the dried residue. The samples were heated in $4-\mathrm{ml}$ sealed glass vials at $70^{\circ} \mathrm{C}$ for 90 minutes. The resulting silylated metabolites were transferred to small Eppendorf tubes and centrifuged at $13,000 \mathrm{rpm}$ to remove insoluble materials. One microliter of the supernatants was analyzed with an Agilent 7890A/5975A GC-MS system with a DB-5 column. The relative enrichment of metabolites is calculated using IsoCor [75].

\section{${ }^{13} \mathrm{C}$-Glucose and ${ }^{13} \mathrm{C}$-Fatty acid labeling comparison and GC-MS metabolite measurements}

For ${ }^{13} \mathrm{C}$-glucose and ${ }^{13} \mathrm{C}$-fatty acid labeling

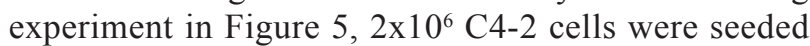
in $10 \mathrm{~cm}$ dishes in CDT-RPMI. On the third day, cells were washed with PBS and plated in medium containing either $10 \mathrm{mM}\left[\mathrm{U}_{-}{ }^{13} \mathrm{C}\right]$-glucose $+75 \mu \mathrm{M}$ unlabeled palmitic acid and unlabeled oleic acid (both bound to fatty acid free bovine serum albumin (BSA) at a molar ratio of $2: 1$ ) or $10 \mathrm{mM}$ unlabeled glucose $+75 \mu \mathrm{M}$ of both [U- $\left.{ }^{13} \mathrm{C}\right]$-palmitic acid and [U- $\left.{ }^{13} \mathrm{C}\right]-$ oleic acid (again BSA bound, from Cambridge Isotopes, Andover, MA). After 6 hours of treatment (control or Combo), metabolites were extracted with $75 \%$ cold methanol/water, 2-ml per plate. Cells were collected with a cell scraper and sonicated on a Branson Sonifor 250 , at a power setting of 2.5 and $20 \%$ duty cycle for 60 seconds. Samples were then centrifuged at 8,500 $\mathrm{rpm}$ at $4^{\circ} \mathrm{C}$ for $15 \mathrm{~min}$. The supernatant was evaporated under nitrogen at $40^{\circ} \mathrm{C}$. The dry residue was silylated by adding $50 \mu \mathrm{L}$ pyridine (anhydrous, 99.8\%) and $50 \mu \mathrm{L} \mathrm{N}$, O-bis(trimethylsilyl)trifluoroacetamide + trimethylchlorosilane (BSTFA + TMCS). Care was taken to exclude water from the mixed samples. They were heated at $55^{\circ} \mathrm{C}$ for 30 minutes, then centrifuged at 13,000 rpm for 10 minutes. One micro-liter of each supernatant was analyzed with an Agilent 7890A/5975A GC-MS system with a DB-5 column. The relative metabolite enrichment was calculated using IsoCor [75]. 


\section{HPLC nucleotide measurements}

For analysis of nucleotide alterations, $2 \times 10^{6}$ cells were seeded in CDT-RPMI in $10 \mathrm{~cm}$ dishes. Cells were treated with control or Combo $+/-$ fatty acid supplementation (50:50 PA: OA; BSA-conjugated) for desired time (1hr, 24 hrs). Cells were harvested by scraping into cold PBS. Cells were pelleted and lysed using $185 \mu \mathrm{L}$ cold $0.5 \mathrm{M}$ Perchloric acid, then incubated on ice for 2 minutes and spun down to remove protein pellet. Supernatant was collected and neutralized with $42 \mu \mathrm{L} 2.5 \mathrm{M} \mathrm{KOH}$ in $1.5 \mathrm{M} \mathrm{K}_{2} \mathrm{HPO}_{4}$, then incubated on ice $2 \mathrm{~min}$ and spun again to remove precipitate. Supernatant containing nucleotides was filtered through $0.22 \mathrm{uM}$ filter and run on HPLC. Extracts were analyzed by ion pair reverse phase HPLC, as described [76]. Analysis was carried out on a Jasco HPLC system. Nucleotides were detected by UV detector at wavelength $254 \mathrm{~nm}$.

\section{RNA isolation and Q-PCR analysis}

Cells were washed with PBS and RNA isolated using Trizol reagent (Invitrogen), according to manufacturer's instructions. cDNA was prepared and gene expression analyzed as previously described on a ViiA-7 Real-Time PCR system [17]. 18S or B2M were used as internal controls. Primer sequences are listed below:

$\boldsymbol{K L K} 3$ - Forward: CCCACTGCATCAGGAACAA; Reverse: GCTGTGGCTGACCTGAAATA

$\boldsymbol{A R}$ - Forward: CCGGAAATGATGGCAGAGAT; Reverse: CTTCACTGGGTGTGGAAATAGA

UBE2C - Forward: TGGTCTGCCCTGTATGATGT; Reverse: AAAAGCTGTGGGGTTTTTCC

FKBP5-Forward: CGGTGATTCAGTATGGGA AGATAG; Reverse: GAAAGGCAGCA AGGAGAAATG.

TMPRSS2-Forward: TGTGCACCTCAAAGACTA AGAA; Reverse: GCCCATGAACTTC CAGAGTAG.

E2F1- Forward: GCTGGACCACCTGATGAATA TC; Reverse: GTCTGCAATGCTACG AAGGT.

ATF4- Forward: GGAGATAGGAAGCCAGACTA CA; Reverse: GGCTCATACAGATGCC ACTATC.

ATF3- Forward: CTGGAAAGTGTGAATGCTGA AC; Reverse: ATTCTGAGCCCGGACA ATAC.

DDIT/CHOP- Forward: CAAGAGGTCCTGTCT TCAGATG; Reverse: GGGTCAAG AGTGGTGAAGATT.

ERN1-Forward: CAAGAGGACAGGCTCAAT CAA; Reverse: CCATCATTAGGATC TGGGAGAAAG.

ATF6- Forward: GGAGCCACTGAAGGAAGA TAAG; Reverse: GTGCTGCTGGAAGC AATAAAG.
BBC3/PUMA- Forward: GTGACCACTGGCAT TCATTTG; Reverse: TCCTCCCT CTTCCGAGATTT.

XBP1s- Forward: CCGCAGCAGGTGCAGG; Reverse: GAGTCAATACCGCCAG AATCCA.

HSPA5/BiP- Forward: AAGGGGAACGTCTGA TTGG; Reverse: ACGGCAAGAAC TTGATGTCC.

ERDJ4- Forward: TCGGCATCAGAGCGCCAA ATCA; Reverse: ACCACTAGTAAAA GCACTGTGTCCAAG.

ERO1LB- Forward: TTCTGGATGATTGCTT GTGTGAT; Reverse: GGTCGCTTCA GATTAACCTTGT.

GADD34- Forward: CCCAGAAACCCCTACT CATGATC; Reverse: GCCCAGACAG CCAGGAAAT.

$\boldsymbol{I L} \boldsymbol{8}$-Forward: TTTGCCAAGGAGTGCTAAAGA; Reverse: CCACTCTCAATCACTCTCAGTTC.

TRIB3- Forward: AGCTGTGTCGCTTTGTCTT; Reverse: CTTGTCCCACAGGGAATCATC.

B2M-Forward: ACC TCC ATG ATG CTG CTT AC; Reverse: GGACTG GTCTTTCTATCTCTTGTAC.

ENTPD5- Forward: GCCAGGGAAGTGTG TGATAA; Reverse: GCTGTCTGCAA AGCCAAAG

18S- Forward: AAATCAGTTATGGTTCCTTTGG TC; Reverse: GCTCTAGAA TTACCAC AGTTATCCAA.

\section{RNA-Seq bioinformatics analysis}

After isolation of RNA using Trizol, Bioanalysis was conducted to confirm quality, using 0.8 RIN value as a cutoff for library preparation. RNA libraries were prepared according to manufacturer instruction using Illumina's TruSeq RNA sample preparation v2 kit using 'Low Sample' and the adapters provided in the kit were used.

All the RNA-seq libraries were sequenced by the Functional Genomics Core at the University of Pennsylvania. Sequencing reads were aligned to the UCSC hg19 using RUM pipeline and differential gene expression analysis were performed using edgeR [77, 78]. As an unbiased interrogation of gene regulation, differentially expressed genes (FDR $<0.0001$, no fold-change cut off) between any pair of conditions were selected for downstream analysis. Hierarchical clustering was performed based on the average log2-scaled gene expression levels using 1 - "Pearson correlation coefficient" as a distance measure under Ward's linkage criterion. Optimal leaf ordering was also performed for better visualization [79]. After the clustering, four most distinct groups of genes were defined among which two major clusters displayed increasing \& gradual response to the combination of ACLYi 
and ENZ. Gene ontology analysis was performed using Homer and top 10 most significant terms were selected for presentation from each of "Biological Process" and "KEGG Pathway" categories [46]. These data have been deposited in NCBI's Gene Expression Omnibus and are accessible through GSE81796 (http://www.ncbi.nlm.nih.gov/geo/ query/acc.cgi?acc=GSE81796).

\section{Immunofluorescence for AR, Ki67 and CCP3}

$5 \times 10^{4}$ cells were seeded in $200 \mu \mathrm{L}$ CDT-RPMI medium in an 8-well chamber-slide and treated as indicated for 5 hours or 24 hours. After treatment, cells were fixed in $4 \%$ paraformaldehyde (PFA), and permeabilized in $0.1 \%$ Triton-X100 in PBS for 10 min. After blocking and incubation with primary and secondary antibodies, cells were then incubated with DAPI (1:1000) and mounted. Antibodies used included: Ki67 (1:200; Leica Biosystem), cleaved caspase 3 (1:200; Cell signaling technologies) and 649-conjugated-donkey-anti-rabbit IgG (1:300).

\section{Oxygen consumption}

Oxygen consumption rate was measured using the Oroboros oxygraph O2K system (Oroboros Instruments). Pre-treated cells were trypsinised and rapidly prepared for assay. Briefly, trypsin was stopped by addition of 5\% CDTFCS RPMI and viable cell number determined by Coulter counter (Beckman-Coulter). Cells were centrifuged (300 $\mathrm{x} \mathrm{g}, 5 \mathrm{~min}, 22^{\circ} \mathrm{C}$ ) and resuspended in PBS. A total of $3 \times 10$ E6 cells were centrifuged $\left(300 \mathrm{x} \mathrm{g}, 5 \mathrm{~min}, 22^{\circ} \mathrm{C}\right)$, resuspended in $37{ }^{\circ} \mathrm{C} 0.5 \mathrm{ml}$ MiRO5 mitochondrial respiration medium (Oroboros Instruments,[80]) and injected into the Oroboros measurement chamber containing $1.7 \mathrm{ml}$ of $37{ }^{\circ} \mathrm{C}$ MiRO5 buffer. For each experiment, control and drug treated cells were measured in parallel. Cells were permeabilized with digitonin (final concentration: $13.6 \mu \mathrm{g} / \mathrm{ml})$. For complex I oxidative phosphorylation (OXPHOS I), glutamate $(9.1 \mathrm{mM})$, malate (1.8 mM), and ADP (3.6 mM) were added. Complex I-and II-dependent oxidative phosphorylation (OXPHOS I + II) was measured by adding succinate $(9.1 \mathrm{mM})$. Complex I- and II-dependent maximal respiration (RESPmax I + II) was measured by adding oligomycin $(2.3 \mu \mathrm{M})$ and the uncoupler FCCP $(0.9 \mu \mathrm{M})$ and complex II-dependent maximal respiration (RESPmax II) was measured after adding rotenone $(0.5 \mu \mathrm{M})$. Residual oxygen consumption was measured after adding antimycin A $(2.3 \mu \mathrm{M})$ and subtracted from other measurements. Raw data analysis was performed using Oroboros Dat Lab (5.0).

\section{Statistical analyses}

Student's two-tailed unpaired t-tests were used for all comparisons of 2 samples, unless otherwise indicated. ANOVA was used for comparisons of more than two groups, as indicated in figure legends.

\section{ACKNOWLEDGMENTS}

We thank the Functional Genomics Core of the University of Pennsylvania for sequencing. This work was supported by an Elsa U. Pardee Research Grant, a Pew Biomedical Scholar Award, and R01CA174761, to KEW. SS was supported by postdoctoral fellowship 5T32CA009140-40. WJC received a University of Pennsylvania Career Services Undergraduate Summer Funding Award. KJW acknowledges R01DK106027 and DK19525. PKK is supported by a Howard Hughes Medical Institute predoctoral fellowship. DCW acknowledges 5RO1-NS021328-30, R33-CA18238401A1, and R01-OD010944-05.

\section{CONFLICTS OF INTEREST}

Authors have no conflicts of interest to declare.

\section{REFERENCES}

1. (2015). Cancer Facts and Figures 2015. American Cancer Society.

2. Wyatt AW and Gleave ME. Targeting the adaptive molecular landscape of castration-resistant prostate cancer. EMBO molecular medicine. 2015; 7:878-894.

3. Mills IG. Maintaining and reprogramming genomic androgen receptor activity in prostate cancer. Nat Rev Cancer. 2014; 14:187-198.

4. Greasley R, Khabazhaitajer M and Rosario DJ. A profile of enzalutamide for the treatment of advanced castration resistant prostate cancer. Cancer Manag Res. 2015; 7:153-164.

5. Sharma NL, Massie CE, Ramos-Montoya A, Zecchini V, Scott HE, Lamb AD, MacArthur S, Stark R, Warren AY, Mills IG and Neal DE. The androgen receptor induces a distinct transcriptional program in castration-resistant prostate cancer in man. Cancer Cell. 2013; 23:35-47.

6. Wang Q, Li W, Zhang Y, Yuan X, Xu K, Yu J, Chen Z, Beroukhim R, Wang H, Lupien M, Wu T, Regan MM, Meyer CA, et al. Androgen receptor regulates a distinct transcription program in androgen-independent prostate cancer. Cell. 2009; 138:245-256.

7. Decker KF, Zheng D, He Y, Bowman T, Edwards JR and Jia L. Persistent androgen receptor-mediated transcription in castration-resistant prostate cancer under androgen-deprived conditions. Nucleic Acids Res. 2012; 40:10765-10779.

8. Scher HI, Beer TM, Higano CS, Anand A, Taplin ME, Efstathiou E, Rathkopf D, Shelkey J, Yu EY, Alumkal J, Hung D, Hirmand M, Seely L, et al. Antitumour activity of MDV3100 in castration-resistant prostate cancer: a phase 1-2 study. Lancet. 2010; 375:1437-1446.

9. Tran C, Ouk S, Clegg NJ, Chen Y, Watson PA, Arora V, Wongvipat J, Smith-Jones PM, Yoo D, Kwon A, Wasielewska T, Welsbie D, Chen CD, et al. Development of 
a second-generation antiandrogen for treatment of advanced prostate cancer. Science. 2009; 324:787-790.

10. Flavin R, Zadra G and Loda M. Metabolic alterations and targeted therapies in prostate cancer. The Journal of pathology. 2011; 223:283-294.

11. Massie CE, Lynch A, Ramos-Montoya A, Boren J, Stark R, Fazli L, Warren A, Scott H, Madhu B, Sharma N, Bon $\mathrm{H}$, Zecchini V, Smith DM, et al. The androgen receptor fuels prostate cancer by regulating central metabolism and biosynthesis. Embo J. 2011; 30:2719-2733.

12. Carrer A and Wellen KE. Metabolism and epigenetics: a link cancer cells exploit. Current opinion in biotechnology. 2014; 34C:23-29.

13. Pietrocola F, Galluzzi L, Bravo-San Pedro JM, Madeo F and Kroemer G. Acetyl Coenzyme A: A Central Metabolite and Second Messenger. Cell Metab. 2015; 21:805-821.

14. Choudhary C, Weinert BT, Nishida Y, Verdin E and Mann M. The growing landscape of lysine acetylation links metabolism and cell signalling. Nat Rev Mol Cell Biol. 2014; 15:536-550.

15. Wellen KE, Hatzivassiliou G, Sachdeva UM, Bui TV, Cross JR and Thompson CB. ATP-citrate lyase links cellular metabolism to histone acetylation. Science. 2009; 324:1076-1080.

16. Robinson D, Van Allen EM, Wu YM, Schultz N, Lonigro RJ, Mosquera JM, Montgomery B, Taplin ME, Pritchard CC, Attard G, Beltran H, Abida W, Bradley RK, et al. Integrative clinical genomics of advanced prostate cancer. Cell. 2015; 161:1215-1228.

17. Lee JV, Carrer A, Shah S, Snyder NW, Wei S, Venneti S, Worth AJ, Yuan ZF, Lim HW, Liu S, Jackson E, Aiello NM, Haas NB, Rebbeck TR, Judkins A, Won KJ, et al. Aktdependent metabolic reprogramming regulates tumor cell histone acetylation. Cell Metab. 2014; 20:306-319.

18. Currie E, Schulze A, Zechner R, Walther TC and Farese RV, Jr. Cellular Fatty Acid Metabolism and Cancer. Cell Metab. 2013.

19. Baenke F, Peck B, Miess H and Schulze A. Hooked on fat: the role of lipid synthesis in cancer metabolism and tumour development. Dis Model Mech. 2013; 6:1353-1363.

20. Porstmann T, Griffiths B, Chung YL, Delpuech O, Griffiths JR, Downward J and Schulze A. PKB/Akt induces transcription of enzymes involved in cholesterol and fatty acid biosynthesis via activation of SREBP. Oncogene. 2005; 24:6465-6481.

21. Porstmann T, Santos CR, Griffiths B, Cully M, Wu M, Leevers S, Griffiths JR, Chung YL and Schulze A. SREBP activity is regulated by $\mathrm{mTORC} 1$ and contributes to Aktdependent cell growth. Cell Metab. 2008; 8:224-236.

22. Duvel K, Yecies JL, Menon S, Raman P, Lipovsky AI, Souza AL, Triantafellow E, Ma Q, Gorski R, Cleaver S, Vander Heiden MG, MacKeigan JP, Finan PM, et al. Activation of a metabolic gene regulatory network downstream of mTOR complex 1. Mol Cell. 2010; 39:171-183.
23. Ettinger SL, Sobel R, Whitmore TG, Akbari M, Bradley DR, Gleave ME and Nelson CC. Dysregulation of sterol response element-binding proteins and downstream effectors in prostate cancer during progression to androgen independence. Cancer Res. 2004; 64:2212-2221.

24. Swinnen JV, Esquenet M, Goossens K, Heyns W and Verhoeven G. Androgens stimulate fatty acid synthase in the human prostate cancer cell line LNCaP. Cancer Res. 1997; 57:1086-1090.

25. Swinnen JV, Van Veldhoven PP, Esquenet M, Heyns W and Verhoeven G. Androgens markedly stimulate the accumulation of neutral lipids in the human prostatic adenocarcinoma cell line LNCaP. Endocrinology. 1996; 137:4468-4474.

26. Beckers A, Organe S, Timmermans L, Scheys K, Peeters A, Brusselmans K, Verhoeven G and Swinnen JV. Chemical inhibition of acetyl-CoA carboxylase induces growth arrest and cytotoxicity selectively in cancer cells. Cancer Res. 2007; 67:8180-8187.

27. Graner E, Tang D, Rossi S, Baron A, Migita T, Weinstein LJ, Lechpammer M, Huesken D, Zimmermann J, Signoretti $\mathrm{S}$ and Loda $\mathrm{M}$. The isopeptidase USP2a regulates the stability of fatty acid synthase in prostate cancer. Cancer Cell. 2004; 5:253-261.

28. Kridel SJ, Axelrod F, Rozenkrantz N and Smith JW. Orlistat is a novel inhibitor of fatty acid synthase with antitumor activity. Cancer Res. 2004; 64:2070-2075.

29. Hatzivassiliou G, Zhao F, Bauer DE, Andreadis C, Shaw AN, Dhanak D, Hingorani SR, Tuveson DA and Thompson CB. ATP citrate lyase inhibition can suppress tumor cell growth. Cancer Cell. 2005; 8:311-321.

30. Gao Y, Islam MS, Tian J, Lui VW and Xiao D. Inactivation of ATP citrate lyase by Cucurbitacin B: A bioactive compound from cucumber, inhibits prostate cancer growth. Cancer Lett. 2014; 349:15-25.

31. Hardie DG, Ross FA and Hawley SA. AMPK: a nutrient and energy sensor that maintains energy homeostasis. Nat Rev Mol Cell Biol. 2012; 13:251-262.

32. Zadra G, Photopoulos C, Tyekucheva S, Heidari P, Weng QP, Fedele G, Liu H, Scaglia N, Priolo C, Sicinska E, Mahmood U, Signoretti S, Birnberg N and Loda M. A novel direct activator of AMPK inhibits prostate cancer growth by blocking lipogenesis. EMBO molecular medicine. 2014; 6:519-538.

33. O'Brien AJ, Villani LA, Broadfield LA, Houde VP, Galic S, Blandino G, Kemp BE, Tsakaridis T, Muti P and Steinberg GR. Salicylate activates AMPK and synergizes with metformin to reduce the survival of prostate and lung cancer cells ex vivo through inhibition of de novo lipogenesis. Biochem J. 2015.

34. Xiang X, Saha AK, Wen R, Ruderman NB and Luo Z. AMP-activated protein kinase activators can inhibit the growth of prostate cancer cells by multiple mechanisms. Biochem Biophys Res Commun. 2004; 321:161-167.

35. Choudhury Y, Yang Z, Ahmad I, Nixon C, Salt IP and Leung HY. AMP-activated protein kinase (AMPK) as 
a potential therapeutic target independent of PI3K/Akt signaling in prostate cancer. Oncoscience. 2014; 1:446-456. doi: 10.18632/oncoscience.49.

36. Cai L, Sutter BM, Li B and Tu BP. Acetyl-CoA Induces Cell Growth and Proliferation by Promoting the Acetylation of Histones at Growth Genes. Mol Cell. 2011; 42:426-437.

37. Shi L and Tu BP. Acetyl-CoA induces transcription of the key G1 cyclin CLN3 to promote entry into the cell division cycle in Saccharomyces cerevisiae. Proc Natl Acad Sci U S A. $2013 ; 110: 7318-7323$.

38. Donohoe DR, Collins LB, Wali A, Bigler R, Sun W and Bultman SJ. The Warburg effect dictates the mechanism of butyrate-mediated histone acetylation and cell proliferation. Mol Cell. 2012; 48:612-626.

39. Shah S, Prasad S and Knudsen KE. Targeting pioneering factor and hormone receptor cooperative pathways to suppress tumor progression. Cancer Res. 2012; 72:1248-1259.

40. Carver BS, Chapinski C, Wongvipat J, Hieronymus H, Chen Y, Chandarlapaty S, Arora VK, Le C, Koutcher J, Scher H, Scardino PT, Rosen N and Sawyers CL. Reciprocal feedback regulation of $\mathrm{PI} 3 \mathrm{~K}$ and androgen receptor signaling in PTEN-deficient prostate cancer. Cancer Cell. 2011; 19:575-586.

41. Mulholland DJ, Tran LM, Li Y, Cai H, Morim A, Wang S, Plaisier S, Garraway IP, Huang J, Graeber TG and Wu H. Cell autonomous role of PTEN in regulating castrationresistant prostate cancer growth. Cancer Cell. 2011; 19:792-804.

42. Young RM, Ackerman D, Quinn ZL, Mancuso A, Gruber M, Liu L, Giannoukos DN, Bobrovnikova-Marjon E, Diehl JA, Keith B and Simon MC. Dysregulated mTORC1 renders cells critically dependent on desaturated lipids for survival under tumor-like stress. Genes Dev. 2013; 27:1115-1131.

43. Griffiths B, Lewis CA, Bensaad K, Ros S, Zhang Q, Ferber EC, Konisti S, Peck B, Miess H, East P, Wakelam M, Harris AL and Schulze A. Sterol regulatory element binding protein-dependent regulation of lipid synthesis supports cell survival and tumor growth. Cancer Metab. 2013; 1:3.

44. Qiu B and Simon MC. Oncogenes strike a balance between cellular growth and homeostasis. Semin Cell Dev Biol. 2015; 43:3-10.

45. Pearce NJ, Yates JW, Berkhout TA, Jackson B, Tew D, Boyd H, Camilleri P, Sweeney P, Gribble AD, Shaw A and Groot PH. The role of ATP citrate-lyase in the metabolic regulation of plasma lipids. Hypolipidaemic effects of SB-204990, a lactone prodrug of the potent ATP citratelyase inhibitor SB-201076. Biochem J. 1998; 334:113-119.

46. Heinz S, Benner C, Spann N, Bertolino E, Lin YC, Laslo P, Cheng JX, Murre C, Singh H and Glass CK. Simple combinations of lineage-determining transcription factors prime cis-regulatory elements required for macrophage and B cell identities. Mol Cell. 2010; 38:576-589.
47. Wang M and Kaufman RJ. The impact of the endoplasmic reticulum protein-folding environment on cancer development. Nat Rev Cancer. 2014; 14:581-597.

48. Sheng X, Arnoldussen YJ, Storm M, Tesikova M, Nenseth HZ, Zhao S, Fazli L, Rennie P, Risberg B, Waehre H, Danielsen H, Mills IG, Jin Y, Hotamisligil G and Saatcioglu F. Divergent androgen regulation of unfolded protein response pathways drives prostate cancer. EMBO molecular medicine. 2015; 7:788-801.

49. Marciniak SJ, Yun CY, Oyadomari S, Novoa I, Zhang Y, Jungreis R, Nagata K, Harding HP and Ron D. CHOP induces death by promoting protein synthesis and oxidation in the stressed endoplasmic reticulum. Genes Dev. 2004; 18:3066-3077.

50. Song B, Scheuner D, Ron D, Pennathur S and Kaufman RJ. Chop deletion reduces oxidative stress, improves beta cell function, and promotes cell survival in multiple mouse models of diabetes. J Clin Invest. 2008; 118:3378-3389.

51. Qing G, Li B, Vu A, Skuli N, Walton ZE, Liu X, Mayes PA, Wise DR, Thompson CB, Maris JM, Hogarty MD and Simon MC. ATF4 regulates MYC-mediated neuroblastoma cell death upon glutamine deprivation. Cancer Cell. 2012; 22:631-644.

52. Zinszner H, Kuroda M, Wang X, Batchvarova N, Lightfoot RT, Remotti H, Stevens JL and Ron D. CHOP is implicated in programmed cell death in response to impaired function of the endoplasmic reticulum. Genes Dev. 1998; 12:982-995.

53. Little JL, Wheeler FB, Fels DR, Koumenis C and Kridel SJ. Inhibition of fatty acid synthase induces endoplasmic reticulum stress in tumor cells. Cancer Res. 2007; 67:1262-1269.

54. Qiu B, Ackerman D, Sanchez DJ, Li B, Ochocki JD, Grazioli A, Bobrovnikova-Marjon E, Diehl JA, Keith B and Simon MC. HIF2alpha-Dependent Lipid Storage Promotes Endoplasmic Reticulum Homeostasis in Clear-Cell Renal Cell Carcinoma. Cancer Discov. 2015; 5:652-667.

55. Volmer R and Ron D. Lipid-dependent regulation of the unfolded protein response. Curr Opin Cell Biol. 2015; 33:67-73.

56. Jurmeister S, Ramos-Montoya A, Neal DE and Fryer LG. Transcriptomic analysis reveals inhibition of androgen receptor activity by AMPK in prostate cancer cells. Oncotarget. 2014; 5:3785-3799. doi: 10.18632/oncotarget.1997.

57. Chen D, Banerjee S, Cui QC, Kong D, Sarkar FH and Dou QP. Activation of AMP-activated protein kinase by 3,3'-Diindolylmethane (DIM) is associated with human prostate cancer cell death in vitro and in vivo. PLoS One. 2012; 7:e47186.

58. Shen M, Zhang Z, Ratnam M and Dou QP. The interplay of AMP-activated protein kinase and androgen receptor in prostate cancer cells. J Cell Physiol. 2014; 229:688-695.

59. Schoors S, Bruning U, Missiaen R, Queiroz KC, Borgers G, Elia I, Zecchin A, Cantelmo AR, Christen S, Goveia J, Heggermont W, Godde L, Vinckier S, et al. Fatty acid 
carbon is essential for dNTP synthesis in endothelial cells. Nature. 2015; 520:192-197.

60. Tennakoon JB, Shi Y, Han JJ, Tsouko E, White MA, Burns AR, Zhang A, Xia X, Ilkayeva OR, Xin L, Ittmann MM, Rick FG, Schally AV and Frigo DE. Androgens regulate prostate cancer cell growth via an AMPK-PGC-1alphamediated metabolic switch. Oncogene. 2013.

61. Schlaepfer IR, Rider L, Rodrigues LU, Gijon MA, Pac CT, Romero L, Cimic A, Sirintrapun SJ, Glode LM, Eckel RH and Cramer SD. Lipid Catabolism via CPT1 as a Therapeutic Target for Prostate Cancer. Mol Cancer Ther. 2014.

62. Schlaepfer IR, Glode LM, Hitz CA, Pac CT, Boyle KE, Maroni P, Deep G, Agarwal R, Lucia SM, Cramer SD, Serkova NJ and Eckel RH. Inhibition of Lipid Oxidation Increases Glucose Metabolism and Enhances 2-Deoxy-2[(18)F]Fluoro-D-Glucose Uptake in Prostate Cancer Mouse Xenografts. Mol Imaging Biol. 2015; 17:529-538.

63. Braakman I and Bulleid NJ. Protein folding and modification in the mammalian endoplasmic reticulum. Annu Rev Biochem. 2011; 80:71-99.

64. Fang M, Shen Z, Huang S, Zhao L, Chen S, Mak TW and Wang $X$. The ER UDPase ENTPD5 promotes protein $\mathrm{N}$-glycosylation, the Warburg effect, and proliferation in the PTEN pathway. Cell. 2010; 143:711-724.

65. Shen Z, Huang S, Fang M and Wang X. ENTPD5, an endoplasmic reticulum UDPase, alleviates ER stress induced by protein overloading in AKT-activated cancer cells. Cold Spring Harb Symp Quant Biol. 2011; 76:217-223.

66. Israelsen WJ and Vander Heiden MG. ATP consumption promotes cancer metabolism. Cell. 2010; 143:669-671.

67. Cancer Genome Atlas Research Network. Electronic address scmo and Cancer Genome Atlas Research N. The Molecular Taxonomy of Primary Prostate Cancer. Cell. 2015; 163:1011-1025.

68. Griss T, Vincent EE, Egnatchik R, Chen J, Ma EH, Faubert B, Viollet B, DeBerardinis RJ and Jones RG. Metformin Antagonizes Cancer Cell Proliferation by Suppressing Mitochondrial-Dependent Biosynthesis. PLoS Biol. 2015; 13:e1002309.

69. Hardie DG. AMP-activated protein kinase: a cellular energy sensor with a key role in metabolic disorders and in cancer. Biochem Soc Trans. 2011; 39:1-13.

70. Gutierrez MJ, Rosenberg NL, Macdougall DE, Hanselman JC, Margulies JR, Strange P, Milad MA, McBride SJ and Newton RS. Efficacy and safety of ETC-1002, a novel investigational low-density lipoprotein-cholesterollowering therapy for the treatment of patients with hypercholesterolemia and type 2 diabetes mellitus. Arterioscler Thromb Vasc Biol. 2014; 34:676-683.

71. Pinkosky SL, Filippov S, Srivastava RA, Hanselman JC, Bradshaw CD, Hurley TR, Cramer CT, Spahr MA, Brant AF, Houghton JL, Baker C, Naples M, Adeli K and Newton RS. AMP-activated protein kinase and ATP-citrate lyase are two distinct molecular targets for ETC-1002, a novel small molecule regulator of lipid and carbohydrate metabolism. J Lipid Res. 2013; 54:134-151.

72. Nguyen HG, Yang JC, Kung HJ, Shi XB, Tilki D, Lara PN, Jr., DeVere White RW, Gao AC and Evans CP. Targeting autophagy overcomes Enzalutamide resistance in castration-resistant prostate cancer cells and improves therapeutic response in a xenograft model. Oncogene. 2014; 33:4521-4530.

73. Zhong J, Ding L, Bohrer LR, Pan Y, Liu P, Zhang J, Sebo TJ, Karnes RJ, Tindall DJ, van Deursen J and Huang H. p300 acetyltransferase regulates androgen receptor degradation and PTEN-deficient prostate tumorigenesis. Cancer Res. 2014; 74:1870-1880.

74. Londono Gentile T, Lu C, Lodato PM, Tse S, Olejniczak SH, Witze ES, Thompson CB and Wellen KE. DNMT1 Is Regulated by ATP-Citrate Lyase and Maintains Methylation Patterns during Adipocyte Differentiation. Mol Cell Biol. 2013; 33:3864-3878.

75. Millard P, Letisse F, Sokol S and Portais JC. IsoCor: correcting MS data in isotope labeling experiments. Bioinformatics. 2012; 28:1294-1296.

76. Kochanowski N, Blanchard F, Cacan R, Chirat F, Guedon E, Marc A and Goergen JL. Intracellular nucleotide and nucleotide sugar contents of cultured $\mathrm{CHO}$ cells determined by a fast, sensitive, and high-resolution ion-pair RP-HPLC. Anal Biochem. 2006; 348:243-251.

77. Grant GR, Farkas MH, Pizarro AD, Lahens NF, Schug J, Brunk BP, Stoeckert CJ, Hogenesch JB and Pierce EA. Comparative analysis of RNA-Seq alignment algorithms and the RNA-Seq unified mapper (RUM). Bioinformatics. 2011; 27:2518-2528.

78. Robinson MD, McCarthy DJ and Smyth GK. edgeR: a Bioconductor package for differential expression analysis of digital gene expression data. Bioinformatics. 2010; 26:139-140.

79. Bar-Joseph Z, Gifford DK and Jaakkola TS. Fast optimal leaf ordering for hierarchical clustering. Bioinformatics. 2001; 17 Suppl 1:S22-29.

80. Fasching M, Fontana-Ayoub, M., Gnaiger, E. Mitochondrial respiration medium-MiR06. Mitochondr Physiol Network. 2014; 14:1-4.

81. Gao J, Aksoy BA, Dogrusoz U, Dresdner G, Gross B, Sumer SO, Sun Y, Jacobsen A, Sinha R, Larsson E, Cerami E, Sander C and Schultz N. Integrative analysis of complex cancer genomics and clinical profiles using the cBioPortal. Sci Signal. 2013; 6:pl1.

82. Cerami E, Gao J, Dogrusoz U, Gross BE, Sumer SO, Aksoy BA, Jacobsen A, Byrne CJ, Heuer ML, Larsson E, Antipin Y, Reva B, Goldberg AP, Sander C and Schultz N. The cBio cancer genomics portal: an open platform for exploring multidimensional cancer genomics data. Cancer Discov. 2012; 2:401-404. 